\title{
ALGUNOS ALCANCES Y ELEMENTOS \\ DE LA RESPONSABILIDAD CIVIL CONTRACTUAL DEL CONSTRUCTOR. ESPECIAL ÉNFASIS EN EL CONTRATO DE CONSTRUCCIÓN BAJO LA MODALIDAD FAST TRACK
}

Aldo Molinari Valdés

Profesor de la Universidad de Chile

Ricardo Padilla Parot

Profesor de la Universidad Diego Portales

\section{INTERROGANTES A RESOLVER.}

En lo que sigue, se desarrollará una serie de cuestiones jurídicas surgidas en una disputa ocurrida durante la ejecución de dos contratos de construcción. En esta controversia judicial, las partes del proceso dedujeron demandas contrapuestas. Por un lado, encontramos al contratista o generalmente llamada en este informe como la "Constructora", quien actúa con la calidad de demandante principal. Por el otro, se presenta el denominado "Administrador" de los contratos de construcción y, adicionalmente, al dueño de la obra o "Mandante", ambos con la calidad de demandantes reconvencionales en juicio.

Las interrogantes a dilucidar son las siguientes, a saber:

a. El papel que representa en materia contractual, la calidad de experto asumida y representada por el constructor.

b. La naturaleza jurídica de los contratos de construcción que las partes suscribieron y el alcance de las obligaciones que de ellos emanan. En particular:

i. El sentido y las implicancias de la modalidad denominada fast track.

ii. La naturaleza de resultado de las obligaciones que asume el constructor.

iii. Si la obligación de poner adecuadamente en funcionamiento las obras (precomisionamiento) corresponde contractualmente a la constructora o al administrador contratado en modalidad EPCM.

iv. La facultad del mandante para modificar el alcance del proyecto.

c. Los remedios al incumplimiento contractual que las partes disponen de acuerdo con la ley y a los contratos. En particular:

i. La aplicación y exigibilidad de las multas contractuales.

ii. Las modalidades de cumplimiento en naturaleza que fueron acordadas en los contratos.

iii. La limitación a la indemnización de daños.

iv. La facultad resolutoria del acreedor. 


\title{
II. ANTECedentes de LA RELACión ENTRE LAS PARTES
}

\author{
A. Sobre el proyecto, \\ las partes y los acuerdos suscritos
}

\section{El proyecto}

El mandante es propietario de una planta productora de mineral ("la planta”). Con el objetivo de aumentar la capacidad productiva de la planta, se encomendó a una empresa administradora de contratos de construcción (el "administrador"), la elaboración de un proyecto de expansión de las instalaciones, a través de un contrato de diseño de ingeniería y administración de la construcción conocidos en la industria bajo la sigla anglosajona EPCM.

\section{Proceso de licitación}

Para adjudicar la construcción, el administrador llevó a cabo dos procesos de licitatorios, en el cual participaron seis empresas constructoras. En el marco de dichos procesos, los proponentes recibieron información técnica de la obra y dispusieron la oportunidad de realizar consultas respecto de los trabajos a ejecutar. Tras el proceso de consultas y respuestas, cinco de las seis empresas ofertaron con el objetivo de adjudicarse la ejecución de los trabajos.

\section{Adjudicación de las obras}

La ejecución del proyecto fue adjudicada a la "constructora", a través de la suscripción de una serie de acuerdos que culminaron en la celebración de dos contratos de construcción, a saber:

i) Montaje electromecánico $\mathrm{C} 1$ y

ii) Montaje electromecánico C2 (conjuntamente referidos como "los contratos"1).

\section{B. Generalidades de los contratos}

4 Objetivo de los contratos

De acuerdo con los contratos, las obras encomendadas a la constructora eran aquellas especificadas en las bases técnicas, consistentes en trabajos de montaje de equipos, cañerías, sistemas eléctricos, estructuras e instalación de instrumentos

${ }^{1}$ Forman parte integrante de estos contratos: (1) Carta de adjudicación y orden parcial de proceder. (2) Acuerdo comercial. (3) Respuestas a consultas de los proponentes y aclaraciones de la licitación, consultas y respuestas serie n. ${ }^{\circ} 1$ y 2. (4) Bases técnicas. (5) Bases administrativas especiales (BAE). (6) Bases administrativas generales (BAG); (7) Bases técnicas (incluye especificaciones, planos y todos los documentos de orden técnico entregados durante el proceso de licitación). (8) Bases comerciales; (9) Cronograma de ejecución del contrato. (10) Requerimientos para el plan de calidad del subcontratista. (11) Oferta del subcontratista. 
de control y medición. Agrega el contrato, que en caso de que las partidas a construir se encontrasen descritas en los documentos técnicos y contractuales de manera general, la constructora debía "realizar cualquier trabajo o actividad que pueda entenderse como necesaria y requerida para su adecuada ejecución”.

\section{Plazo del contrato}

De acuerdo con los contratos, la constructora disponía de 174 días y 180 días corridos, respectivamente para montaje electromecánico $\mathrm{C} 1$ y $\mathrm{C} 2$, para ejecutar la totalidad de las obras y servicios encargados por el mandante.

\section{Precio del contrato}

El precio de los contratos se pactó en una cifra superior a los trece mil quinientos millones de pesos, bajo una modalidad contractual de carácter doble denominada en las BAG, "a serie de precios unitarios con suma alzada de gastos generales y utilidades". Conforme a las mismas BAG, un contrato a precios unitarios era aquel en que se paga al contratista

"por cada unidad mesurable de la obra material, trabajo o servicio que haya sido correctamente ejecutado en cada una de las partidas establecidas en el itemizado de presupuesto",

pero en el cual no se "incluyen los gastos generales ni las utilidades del subcontratista, por estar ellos contenidos por separado en una suma alzada fija". De acuerdo con el contrato, solo el costo directo de los trabajos se encontraban sujeto a la modalidad de precios unitarios. Finalmente, el término costo directo es definido por las BAG como el

"costo de los recursos imputables directamente a una determinada partida, tales como mano de obra, materiales, insumos maquinaria, equipos u otros de similar entidad o naturaleza".

\section{La calidad de experto}

7. Las consecuencias de actuar contractualmente como experto

Que la constructora haya actuado a lo largo de todo el íter contractual como una empresa de carácter experta, es un hecho establecido en el proceso, pues así lo reconoce expresamente la "Constructora" en su demanda principal. En efecto, la demanda principal dedica todo un capítulo destinado a explicar cómo es que la constructora

“es una compañía de vasta trayectoria y prestigio en el ámbito de la construcción y del montaje industrial, la cual ha participado en importantes proyectos y licitaciones a nivel nacional". 
A la luz de lo dispuesto por el art. 1713 del Código Civil, no cabe duda alguna que tales expresiones deben ser calificadas como confesión de un hecho personal de la misma parte y que "no podrá el confesante revocarla, a no probarse que ha sido el resultado de un error de hecho".

Estando reconocida, entonces, la calidad de experto de la constructora, se hace necesario analizar, luego, las consecuencias jurídicas que acarrea tal expertise para los efectos de las obligaciones contractuales voluntariamente asumidas.

En nuestra opinión, la calidad de experto de un contratante necesariamente agrava el nivel de diligencia y cuidado que debe emplear el deudor al ejecutar sus obligaciones. Aquello no solo proviene de la literalidad del vínculo jurídico que une a las partes, sino, también, de aquel deber de lealtad que surge cuando las declaraciones de una parte suscitan en la otra una especial confianza respecto de una determinada circunstancia o hecho que la ha llevado en definitiva a contratar. De allí que el estándar de conducta exigible a quien emprende tareas delicadas y complejas tratándose de un profesional, resulte ser comparativamente superior al aplicable respecto de quienes carecen de esas calificaciones.

Lo anterior fue muy tempranamente reconocido por importante autores en derecho francés. Así, Henri Mazeaud y André Tunc sostenían:

"parece evidente que el tipo del buen padre de familia propuesto como modelo para el deudor por el artículo 1137 del Código Civil, no podría convenir para la determinación del contenido de la obligación profesional (...) las mismas razones de seguridad social que llevan a exigirle a un particular que ponga en el cumplimiento de su obligación 'todos los cuidados de un buen padre de familia', deben llevar a exigir del profesional que ponga en el cumplimiento de la suya 'todos los cuidados de un buen profesional'; u más exactamente, todos los cuidados de un buen profesional de su especialidad (...) esa especialización del profesional lleva normalmente consigo un aumento del grado de su obligación con respecto a la obligación del particular"”.

En ello coinciden, también, importantes autores argentinos ${ }^{3}$ y nacionales. ${ }^{4}$ Por lo demás, de la misma manera se ha pronunciado la jurisprudencia nacional ${ }^{5}$.

${ }^{2}$ Mazeaud y Tunc (1961), pp. 438-440.

${ }^{3}$ Kemelmajer y Parellada (1997), p. 145.

${ }^{4}$ De acuerdo con el profesor Enrique Barros: "Suele ser relevante para fijar el nivel de cuidado que el autor del daño actúe como un experto. Esta condición es especialmente importante para determinar el nivel de cuidado debido en sede contractual (...). Si alguien desarrolla una actividad que plantea requerimientos profesionales particularmente exigentes o un cierto conocimiento o experiencia práctica calificada, la confianza comprometida respecto de su conducta es correlativamente mayor (...). El estándar de cuidado es el exigible a quien emprende tareas delicadas y resulta ser comparativamente superior al aplicable respecto de quienes carecen de esas calificaciones", BARROS (2006), p. 89.

${ }^{5}$ Consejo de Defensa del Estado con Empresa Constructora Bravo Izquierdo (2014): "La demandada es una empresa constructora que se encontraba sometida a un contrato que fue 
Lo anterior resulta indudable, no solo por la confesión de la Constructora, referida en forma precedente, sino, más aun, por las declaraciones efectuadas a propósito de la relación contractual. En efecto, en el caso en estudio se agregan

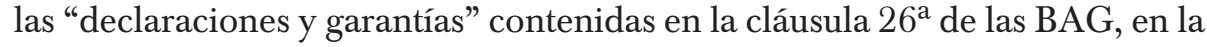
que la constructora aseguró -y el mandante confío- que el contratista dispondría un claro nivel de expertise durante la ejecución de los trabajos. Dichas declaraciones, según se desarrollará, son una genuina asunción de riesgo respecto de situaciones de hecho y representaciones del deudor para con el acreedor.

Refuerza -además- lo anterior, el indudable carácter intuito personae que revisten los contratos de construcción. En efecto, dentro de los márgenes de la razón, todo contrato de construcción se celebra sobre la base del dominio de la lex artis del constructor, esto es, su "saber-hacer, la experiencia profesional, la corrección y el prestigio bien ganado"; todos elementos que, como es lógico, tienden a generar una confianza recíproca entre los contratantes, de lo cual no puede constituir los presentes contratos una excepción.

\section{Las representaciones y garantías contractuales}

\section{Las declaraciones y garantías contractuales generan responsabilidad de carácter estricta}

Las BAG establecieron una serie de declaraciones y garantías comprometidas por la constructora al mandante. Ambas partes elevaron dichas declaraciones a la calidad de esenciales para contratar. Este tipo de cláusulas -conocidas en inglés como representations \& warranties- son una técnica contractual tomada desde el Common Law. Su función principal es servir como mecanismo de resguardo ante aquellos casos en que el deudor no proporciona toda la información requerida, o en aquellas circunstancias en que la información entregada por el mismo deudor resulta ser falsa o se aleja de la realidad de la cosa vendida o de la prestación de servicios ofertada. En otras palabras, son garantías sobre la calidad del objeto del contrato, ya sea la prestación una cosa o un servicio.

En nuestro derecho, el incumplimiento a estas declaraciones contractuales genera una responsabilidad aún más estricta que la infracción de una obligación de resultado, pues la infracción a estas declaraciones no admiten excusa alguna, ya sea en sede de culpabilidad (diligencia) o causalidad (caso

celebrado precisamente por la mayor experticia de la misma, es decir, que la contratante no podía sino esperar un cumplimiento total y profesional en conformidad a la tantas veces citada lex artis constructiva. De manera que no puede excusarse -la demandada- de su responsabilidad, amparándose en una supuesta incongruencia entre las especificaciones técnicas y la obra que ejecutaba, ello por cuanto ha quedado plausiblemente establecido que no dio cumplimiento debido a todos y cada uno a esos requerimientos especificados".

${ }^{6}$ Ríos y Molina (2016), pp. 42-43. Estos autores agregan que el contrato de construcción se celebra en especial atención a las cualidades "personales de los sujetos contratantes, así como sus competencias y habilidades para cumplir la obligación de resultado que emana de la naturaleza del convenio". 
fortuito), por lo que deben ser siempre indemnizadas. Así Enrique Barros y Nicolás Rojas sostienen:

"mientras que la responsabilidad civil (no la garantía restitutoria) en materia de vicios ocultos está dada por alguna forma de culpa intencional (que tiene por antecedente el conocimiento), la responsabilidad por garantías es estricta en el más puro sentido, porque no admite excusa alguna y comprende incluso el caso fortuito (...). Por eso no resulta admisible, por incompatible con la función de la declaración alegar que por hechos irresistibles o inimputables resultó ser falso lo que se declaró a la contraparte como verdadero. Esta es la interpretación que resulta funcionalmente coherente con los fines de las garantías contractuales y con la práctica contractual que las recoge"7.

Otro tanto ocurre en derecho comparado, habiéndose sostenido sin dificultades:

“en cambio, en las manifestaciones y garantías el vendedor realiza una afirmación explícita sobre el objeto del contrato, que generará su responsabilidad por la inexistencia del hecho o la circunstancia (o su existencia, si la manifestación se refería a un suceso negativo), y ello aun cuando no se pueda probar por el comprador el fraude, la intención dolosa $\mathrm{o}$, incluso, el mero conocimiento del hecho por parte del vendedor"

9. El incumplimiento de una declaración y garantía obliga al deudor a resarcir el interés contractual afectado

Estos informantes no pueden, sino coincidir con aquellas afirmaciones que sostiene que las obligaciones que imponen este tipo de estipulación no consisten en un simple dar, hacer o no hacer. Tampoco significan

"obligarse a que la realidad sea diferente, algo imposible, sino garantizar el interés del otro contratante en un determinado estado de la realidad, indemnizándole en los casos en que la realidad sea de otro modo" ${ }^{9}$.

Sobre el punto, la doctrina española enseña con meridiana claridad que quien promete un estado de cosas, responde si ese estado de cosas no corresponde a la realidad:

“en primer lugar, la realización de una manifestación o representación cualquiera crea un riesgo directamente atribuible a la parte que lo hace,

\footnotetext{
${ }^{7}$ Barros y Rojas (2009), pp. 518-520.

${ }^{8}$ Gómez (2007), p. 35.

${ }^{9}$ Díez-Picazo et al. (2002), pp. 318-319.
} 
pues es ésta la que sostiene la validez de una afirmación, que en caso contrario permanecería ajena al circuito de intereses afectados por el contrato. En segundo lugar, quien representa un estado de hecho garantiza su existencia y por tanto, promete que existe o existirá un estado de cosas. En este punto, este estado de las cosas no es ya un simple azar, un riesgo ajeno al contrato, sino el objeto de una promesa, de un deber ser que se imputa de modo obligatorio a una conducta" ${ }^{10}$.

En el caso que se revisa, entre las cuestiones garantizadas por la constructora al mandante durante la ejecución de las obras, encontramos, entre otras, su grado de conocimiento técnico y experiencia para ejecutar las obras, pero también, principalmente, el hecho de contar con personal suficiente, apto, capaz e idóneo para cumplir con las exigencias técnicas del contrato. Así consta en la cláusula 26 de las BAG, literales d. e. y h. Asimismo, en la cláusula 6.0 $\mathrm{BAG}^{11}$.

De este modo, la constructora se transformó en un verdadero garante de todos los perjuicios que el mandante pudiera sufrir ${ }^{12}$ de verse perjudicado por la discordancia entre lo acontecido en la realidad de la obra y lo declarado contractualmente $^{13}$. En efecto, al formar dichas declaraciones y garantías, parte del contenido obligacional de los contratos, todos los daños a resarcir al mandante no solo le eran previsibles para la constructora al momento de contratar, sino que aquella no puede excusarse de los mismos ni aun acreditando su máxima diligencia.

\section{LA NATURALEZA JURÍDICA DE LOS CONTRATOS Y EL ALCANCE DE LAS OBLIGACIONES QUE DE AQUELLOS EMANAN}

\section{A. Contratos de construcción de naturaleza Fast Track}

10. Las partes no discuten la naturaleza de los contratos, sino el alcance de la expresión "fast track" referida en lo específico a la época de entrega del diseño del proyecto

Las partes del arbitraje se encuentran contestes en que el vínculo jurídico que las une proviene de dos contratos de construcción con el carácter "fast track". Aquello se lee transversalmente en los escritos de discusión. Por ejemplo, la constructora señala la importancia de cumplir con ciertos elementos que

${ }^{10}$ García (2015), p. 70.

${ }^{11}$ Cláusula 26 de las BAG, literales d. e. y h. Asimismo, la cláusula 6.0 de las BAG establece: "Todo el personal que preste servicios al Subcontratista o a sus terceros deberá poseer los requisitos de capacidad, conocimiento, idoneidad y experiencia acordes con el desempeño específico a ejecutar (...)."

${ }^{12}$ Alcalde (2008), p. 248.

${ }^{13}$ Morales (2014), pp. 79-80. 
componen este contrato, pues "se trata de un proyecto con el carácter fast track". Por su parte, el mandante y el administrador señalan que "una de las principales características de los contratos consiste en que éstos tuvieron la naturaleza de fast track".

Sin embargo, las partes discrepan en lo que el término fast track implica, y cómo es que aquel repercute en la interpretación y cumplimiento de ciertas obligaciones contractuales. Señala la constructora:

"nuestra representada siempre se refirió al concepto de fast track bajo el contexto de un contrato que ha de ejecutarse en un breve plazo (...), todo lo cual hace necesario que la ingeniería básica y de detalles se encuentre disponible desde los inicios del mismo".

En cambio, el mandante y el administrador indican:

"los contratos fast track son, por definición, aquellos que los contratistas comienzan a ejecutar sus obras sin esperar a que la ingeniería esté terminada y entregada”.

11. El sentido y alcance de la modalidad fast track debe ser buscado en el derecho anglosajón

286 Basta la nomenclatura empleada por las partes - fast track- para dar cuenta de que aquel concepto no proviene de, ni se encuentra en nuestra legislación. En efecto, en el derecho nacional es más bien desconocida la terminología, siendo escasas las referencias a esta modalidad de contrato de construcción.

Por ello es que, a juicio de estos informantes, se hace imperante recurrir a la doctrina y jurisprudencia anglosajona para determinar el contenido de las obligaciones de naturaleza fast track del mandante y la constructora. En este sentido, se ha definido fast track ${ }^{14}$ como

“aquel método de construcción en el cual la construcción comienza antes de la terminación de todo el diseño (...). Pareciese ser que la regla generalmente aceptada es que si la construcción comienza con menos

${ }^{14}$ También ha sido definido como una "técnica de compresión de la programación. En fast-tracking, las fases o actividades que normalmente se ejecutaran dentro de una secuencia, se realizan en paralelo; en otras palabras ellas están traslapadas". Lo señalado es una traducción libre de lo siguiente: "It) identifies fast-tracking as a schedule compression technique. In fasttracking, phases or activities that normally would be done in sequence are performed in parallel; in other words they are overlapped". Dhghan y Ruwanpura (2011), p. 1959. Asimismo, se ha dicho que una "simple definición de fast tracking es aquel proceso de traslapar en forma paralela, actividades o fases secuenciales, con el objeto de comprimir la programación del proyecto". Lo indicado es una traducción libre de la siguiente cita: "A simple definition of fast tracking is the process of overlapping sequential activities or phases in parallel to compress the Project Schedule". AlHomadi et al. (2011), p. 1967. 
de la mitad de los planos y especificaciones terminadas, el proyecto puede ser considerado como fast track"15.

En efecto, precisamente

"para mejorar la lentitud del tripartito modo de construcción -confección del diseño del proyecto, seguida de la fijación de precio, para luego la adjudicación del contrato- algunos mandantes han organizados sus proyectos para que comiencen la construcción antes de que los detalles finales de los planos estén terminados" ${ }^{\prime 16}$.

La jurisprudencia estadounidense se ha pronunciado en el mismo sentido, señalando que proceder de manera fast track

"en el negocio de la construcción, significa que la construcción comienza bajo una programación simultánea con el diseño. En otras palabras, en este caso el [contratista], tenía que comenzar la construcción antes que el diseño estuviera totalmente finalizado y los planos completamente coordinados" $"$.

\section{De este modo, el fast tracking}

"difiere del modo tradicional de construcción, pues puede iniciar mientras el diseño de la ingeniería se completa (...). Idealmente esto significa que el proyecto deberá estar terminado antes de lo normal"18.

${ }^{15}$ SQuires y Murphy (1983), pp. 56-57. La cita transcrita, corresponde a una traducción libre del siguiente pasaje: "A method of construction by which actual construction is commenced prior to the completition of all design (...). The generally accepted rule appears to be that if construction begins with less than half of the plans and specifications complete, the project can be considered a fast track project".

${ }^{16}$ La cita transcrita corresponde a una tradición libre del siguiente pasaje: "In order to improve the slow pace of the tri-partite approach-completion of drawings, followed by pricing, then award-some owners have organized their projects to begin preliminary construction before the final details of the drawings are completed". FrIEDLANDER (2011).

${ }^{17}$ Roberts \& Schaefer Co. con Hardaway Co. (1998). En el mismo sentido, se ha señalado: "en su lugar, los planos de arquitectura y especificaciones son definidas y modificadas mientras la construcción del edificio progresa. La ventaja del método fast track, en oposición a aquel de construcción con la totalidad de los planos definidos, es que hace posible que la construcción comience en una etapa mucho más temprana". Lo anterior es una traducción libre del siguiente pasaje: "Under the fast track method, construction on a building begins before a final set of fully coordinated plans is completed. Rather, the architectural plans and specifications are designed and modified as the building's actual construction progresses. The advantage of the fast track method, as opposed to building from plans completed at the outset, is that it enables construction to begin at a much earlier stage in the project". Marriott Corporation con Dasta Construction Company (1994). También puede consultarse Comstock \& Company, Inc. con United Engineers \& Constructors Inc. (1989).

${ }^{18}$ La cita transcrita corresponde a una tradición libre del siguiente pasaje referido al fast-tracking: "It differs from the tradicional method in that construction can begin before design is completed (...). Ideally this means that the project should be completed sooner”. SWEET y SCHNEIER (2009), p. 360. 
Nos parece, finalmente, que las escasas referencias efectuadas por la doctrina nacional apuntan también -inequívocamente- hacia la interpretación realizada por el mandante y el administrador ${ }^{19}$. Como se podrá apreciar el punto se encuentra totalmente zanjado.

12. La tesis de la constructora no tiene cabida a la luz de la naturaleza fast track de los contratos

El principal argumento del constructor se funda en que

"la ejecución de un proyecto como el de autos, el cual tenía un plazo acotado de ejecución, suponía un requisito básico que en este caso fue incumplido por las demandadas, consistente en que la ingeniería de detalles estuviese lista desde el día uno del proyecto”.

Pero aquella afirmación pugna con la naturaleza fast track de los contratos convenidos por las partes. Es dicha naturaleza la que forzosamente apunta a concluir que cuando la constructora debía comenzar a ejecutar las obras, el mandante no tenía la obligación de proporcionarle la totalidad de los planos o la ingeniería completamente desarrollada. Es más, de acuerdo con los autores y fallos americanos que antes hemos citados, la constructora ni siquiera debía esperar la entrega de la mitad de aquellos antecedentes técnicos.

13. Del tenor de los contratos, tampoco aparece que las partes hayan querido modificar su naturaleza fast track

Sugiere la constructora que la obligación del mandante, de entregar todos los planos en la fecha de inicio de los trabajos, provendría de la cláusula 4.0 de las Bases Técnicas de ambos contratos. En particular, el argumento se sustenta en aquella parte de la cláusula que indica: "una vez adjudicado el contrato, se entregarán los planos en su última revisión y aprobados para la construcción".

Estimamos que, por definición, en los contratos de naturaleza fast track, la ingeniería, diseño y planos de arquitectura, se encuentran desarrollados en

${ }^{19}$ De acuerdo con Prado (2014), p. 775, "bajo el método turnkey [llave en mano], se encuentra el fast track que permite proceder aun cuando el diseño no esté completo". Asimismo, de acuerdo con Ríos y Molina (2016), p. 124, "en la actualidad es bastante usual, ante la necesidad de concretar proyectos con mayor velocidad, que la ingeniería que deba desarrollar el mandante para ser entregada al contratista, se desarrolle muchas veces en paralelo al avance de las obras, en una modalidad denominada Fast Track". Desde la perspectiva de la ingeniería civil, se ha señalado: "un caso particular de esta situación, son los llamados proyectos fast track, en los cuales comienza su construcción cuando la ejecución del diseño aún no se encuentra terminada. La idea de los proyectos fast track, es aplicarlo a obras que permitan una rápida recuperación de la inversión por parte del mandante (por ejemplo las obras destinadas a centro comerciales o mall), de modo que es más conveniente asegurar un inicio de funcionamiento del proyecto lo antes posible, que esperar que el diseño este totalmente terminado para seguir en forma secuencial con la construcción del proyecto. VERA (2007), p. 12. 
alrededor de un 50\% al inicio de la construcción. Podría afirmarse que, incluso, en un porcentaje mayor, pero jamás completamente terminada para su entrega total desde el inicio de las obras. Entonces, cabe preguntarse si las partes mediante la introducción del precepto antes citado en las Bases Técnicas, tenían la intención -como lo pretende la constructora-de modificar aquella parte de la naturaleza fast track. El mandante y el administrador sostienen la negativa.

Existiendo controversia entre las partes respecto del sentido y alcance de la estipulación contractual, cobran aplicación las reglas de interpretación contractual establecidas en el art. 1560 y siguientes del Código Civil. La expresión "una vez..." ${ }^{20}$ y "se entregaran los planos...", son, desde luego, las expresiones que han causado esta controversia. De su lectura se hace aparente una confusión del contenido obligacional, respecto de si el administrador a nombre del mandante debía entregar la totalidad de los planos a la constructora inmediatamente de adjudicado los contratos. Nos parece que no.

La primera razón proviene de la etapa de formación del consentimiento. Previo a la suscripción de los contratos, la constructora participó en un proceso de licitación en el cual se habría representado que a la época en que se le harían entrega de los terrenos para iniciar la construcción, la ingeniería y los planos definitivos no estarían completamente desarrollados ${ }^{21}$. En esto el mandante y el administrador no indujeron a error a la constructora, la cual decidió libre y voluntariamente contratar sin reparar ni observar de manera previa y negativa, la falta de terminación del diseño del proyecto. Es más, durante la etapa de licitación ninguno de los oferentes realizó objeción alguna respecto de esta circunstancia del proyecto.

En segundo lugar, la modalidad de la cláusula del precio también devela que el diseño del proyecto estaba incompleto ${ }^{22}$. En aquella cláusula se estableció que el precio del costo directo de las obras se pactaba a precios unitarios y no a suma alzada, pues en la medida que se definiera la ingeniería y se determinaran las partidas específicas a construir -dentro del catálogo de ítems que previamente fueron valorados en el presupuesto ofertado- la constructora tendría derecho a recibir como precio la cantidad de "obra material, trabajo o servicios que haya sido correctamente ejecutado", en los términos de la cláusula 1.2 de las BAG.

Finalmente, no existe alguna modificación expresa o tácita de los contratos respecto de la época en que se entregarían los planos y la ingeniería a la constructora. En los hechos, el mandante a través del administrador, hizo entrega

${ }^{20}$ Según el Diccionario de la lengua española, "una vez" supone que se ha de ejecutar o se ha ejecutado algo, o para sentar su certidumbre o existencia. Disponible http://dle.rae.es/srv/ fetch?id=biPx6YF. [Fecha de consulta: 15 de diciembre de 2017].

${ }^{21}$ De acuerdo con la serie de consultas y respuestas de la etapa de licitación.

${ }^{22}$ Como señalan Ríos y Molina (2016), pp. 390-394, la modalidad fast track tiene lugar "especialmente en los contratos pactados a serie de precios unitarios, en los cuales se cuenta con un detalle de muchas partidas de precios, que se van aplicando a las obras que luego se van definiendo en la ingeniería". 
del diseño del proyecto de forma parcelada, en la medida que la construcción evolucionaba.

Por ello, es que para estos informantes las reglas de interpretación intrínseca de los contratos, establecidas en el inc. $1^{\circ}$ de los arts. 1563 y 1564 del Código Civil, parecen las más adecuadas de emplear para resolver la aparente obscuridad de la cláusula en cuestión. Ambas reglas apuntan a otorgar a las cláusulas contractuales aquel sentido que se condice con la naturaleza del contrato $^{23}$. De esta manera, la naturaleza fast track de los contratos nos hace concluir que, a partir de la adjudicación de los mismos, los planos para construir serían entregados por el mandante a la constructora en la medida que estos se encontraran terminados y según los avances de la construcción; pero la cláusula contractual jamás tuvo la intención de que el diseño del proyecto le fuera entregado en su totalidad a la constructora al inicio de las faenas.

\section{B. Las obligaciones del constructor se encuentran sujetas a una responsabilidad de carácter objetiva}

14. En Chile se reconoce la clasificación de obligaciones de medios y de resultados

No cabe duda que nuestra doctrina ${ }^{24}$ y jurisprudencia ${ }^{25}$ reconocen la distinción entre obligaciones de medios y de resultado. Es más, se sostiene que:

"las obligaciones de resultado son la regla general, considerando que son las más numerosas y que habitualmente las de medios son establecidas excepcionalmente por la ley o mediante disposición contractual expresa" ${ }^{26}$.

La principal función que se ha atribuido a esta clasificación se refiere a la determinación del incumplimiento de la obligación y al hecho generador de la responsabilidad del deudor. En el caso de las de resultado, se les incumple cuando no se ha proporcionado al acreedor la finalidad comprometida en el contrato. En efecto, el deudor se obliga a obtener el fin perseguido por el acreedor en el contrato, asumiendo en todo momento el control de los riesgos que puedan impedir el cumplimiento de su prestación ${ }^{27}$. La obligación de medios, en cambio, se incumple cuando el deudor no se ha comportado con la diligencia debida, pues el elemento culpa (imputabilidad), se identifica con el incumplimiento ${ }^{28}$.

${ }^{23}$ LÓPEZ (2010), pp. 390-394.

${ }^{24}$ Véase Peñailillo (2003), pp. 222-230.

${ }^{25}$ Véase Corte Suprema, sentencia de 10 de diciembre de 2008, rol 1771-2007 y sentencia de 19 de enero de 2016, rol 7215-2014.

${ }^{26}$ Peñailillo (2003), p. 226.

${ }^{27}$ Barcia (2007), pp. 29-44.

${ }^{28}$ Pizarro (2008), pp. 255-265. Sobre el particular, el profesor Enrique Barros ha señalado: "en las obligaciones de resultado es inequívoco que el acreedor tiene derecho a que le sea 


\section{De los contratos emanan obligaciones de resultado para la constructora}

La obligación de la constructora de entregar correcta, completa y oportunamente las obras encomendadas en los contratos, a nuestro entender, y para la mayoría de la doctrina nacional, es una de aquellas de resultado ${ }^{29}$. La constructora se obligó, naturalmente respecto del mandante, a la obtención de lo proyectado en aquellos instrumentos (la ejecución de la planta); teniendo que encaminar toda su actividad para concretar aquel resultado ${ }^{30}$. La Corte Suprema también ha confirmado esta opinión, incluso, en casos en que el contrato no ha sido escriturado por las partes ${ }^{31}$.

\section{Ante obligaciones de resultado, la constructora no puede excusar su incumplimiento mediante la prueba de la diligencia}

$\mathrm{Al}$ haber asumido la constructora una obligación de resultado, el solo incumplimiento respecto de los términos en que se debían entregar las obras al mandante (sin defectos y dentro de los plazos acordados), trae aparejada su responsabilidad civil. No es necesario entrar a la prueba de la diligencia, pues la constructora solo podría exonerarse probando el caso fortuito, esto es, los hechos que han impedido el cumplimiento de su prestación, pues no basta, ni resulta pertinente probar la ausencia de culpa, dado que en este tipo de obligaciones dicho elemento subjetivo es del todo irrelevante ${ }^{32}$.

provocado por el deudor el interés económico perseguido (...). En las obligaciones de medios la expectativa normativa del acreedor se dirige a que el deudor realice los esfuerzos conducentes a obtener esos beneficios perseguidos. En otras palabras, estos últimos no pertenecen al ámbito de responsabilidad del deudor". BARRos (2007), p. 418.

${ }^{29}$ Contreras y Prado (1996), p. 7.

${ }^{30}$ Del Arco y Pons (1991), p. 23. En el derecho nacional se ha sostenido: "el objeto del contrato de construcción no es otro que obtener un resultado que se traduce en la ejecución de la obra encargada por el propietario, sea que el precio lo asuma el constructor o el propietario. Lo que se obtiene de un contrato de construcción es la organización y desarrollo de un conjunto de labores y actividades que se concretan en la realización de la obra, en los términos y condiciones proyectados por el propietario o dueño de la misma”. Ríos y Molina (2016), p. 38.

${ }^{31}$ Inversiones Clarkson con Donoso C., Humberto (2014): “que tratándose de una obligación de hacer de las particulares condiciones que presenta la ejecución de una obra de construcción, la discusión que se ha planteado dice relación con la forma en que ésta debió cumplirse ante la ausencia de un contrato escrito que detallara la especificidad de su realización y los elementos que se han debido utilizar en el desempeño. Sobre este punto no puede dejar de anotarse que era tarea del demandado realizar el estudio del proyecto a ejecutar, objeto del contrato, y dentro de cuyo precio se incluye todo aquello que sea necesario para la correcta terminación y funcionamiento de la instalación, más allá de la determinación de los materiales que se haya acordado utilizar. En efecto, aun cuando la parte que encomienda el trabajo no detalle en forma expresa la manera como el contrato debe cumplirse, en esta especial situación debe mirarse al resultado obtenido luego de ejecutada la obra, de suerte que aquella haya quedado en condiciones de servir para lo que es, respetando los principios constructivos y la lex artis que regla la materia".

${ }^{32}$ Sobre este planteamiento, véase Domínguez (2010), pp. 36-37, Pizarro (2009), pp. 587-593; RodRíGuez (2008), pp. 503-517. En el caso de un incumplimiento contractual a una obligación de resultado, el profesor Enrique Barros ha señalado: "en estos casos el propio incumplimiento 


\section{La obligación de poner adecuadamente en funcionamiento \\ las obras (precomisionamiento) corresponde contractualmente \\ a la constructora y no al administrador contratado \\ en modalidad EPCM}

\section{El precomisionamiento es una labor de construcción}

De acuerdo con la cláusula 1.2 de las BAG, el "precomisionamiento" consiste en trabajos destinados a verificar si las obras fueron ejecutadas correctamente, comprobando de aquel modo si las mismas se encuentran en condiciones de ser utilizadas de acuerdo con las especificaciones del mandante. Desde un punto de vista más jurídico, es una de las tantas actividades que el deudor debe realizar para concretar y cumplir con la obligación de resultado asumida contractualmente con el acreedor.

Las misma cláusula 1.2 de las BAG señala que será el subcontratista quien "empleará un grupo de personal separado de aquellos dedicados a la ejecución del Trabajo". Se especifica en las definiciones contractuales que el "subcontratistas" 33 es la constructora, persona jurídica a quien el "contratista" 34 (el administrador) -en representación del mandante- le ha encomendado los trabajos de construcción.

18. El Administrador no asumió obligaciones

de construcción con el mandante.

Su contrato era de administración en la modalidad EPCM

El administrador fue mandatado por el dueño de la obra para la administración de los trabajos. El mandante no encomendó al administrador la construcción o habilitación de las obras, pues la modalidad del contrato celebrado entre aquellas partes -según indicamos- fue EPCM. Aquello significa que el administrador fue contratado para elaborar y proveer la ingeniería, adquirir suministros y administrar la construcción. De este modo, el mandante contrató directamente a la constructora para ejecutar las obras que serían administradas

puede ser imputado subjetivamente al deudor en la forma de una especie de culpa infraccional, que sólo admite como excusa la prueba del caso fortuito por el deudor (...). Si se asume este enfoque, es posible concluir, al menos en las obligaciones de resultado, que el deudor debiera ser responsable de todo evento que quede bajo su control. Si el acreedor no obtiene el beneficio que le ha sido garantizado debiera tener una pretensión indemnizatoria. En consecuencia para liberarse de responsabilidad, al deudor no le basta probar que ha empleado diligencia, pero que por una causa desconocida se produjo el incumplimiento, sino debe probar la causa de ese incumplimiento y mostrar que ella supera el ámbito de riesgo asumido en virtud del contrato. En otras palabras, la vaga afirmación de que el incumplimiento se produjo por ausencia de culpa no puede ser tenida por excusa suficiente". BARROS (2007), pp. 416-417.

${ }^{33}$ Se establece como definición en las BAG: "Subcontratista: Persona natural o jurídica que ejecuta el trabajo encargado por el Contratista al amparo del Contrato (...)”.

${ }^{34}$ Se define en las BAG: "El Administrador, actuando directamente, o como agente o como mandatario, para efecto de dar cumplimiento con lo dispuesto en el Contrato (...)." 
por el administrador ${ }^{35}$, de manera que si el precomisionamiento es propiamente una labor de construcción para terminar los trabajos encomendados, resulta forzoso concluir que era la constructora quien debía realizarlo. Se trata de una interpretación razonable y, más bien, evidente de los términos contractuales.

19. La constructora argumenta sobre la base de un error de terminología incurrido por las partes durante el proceso de licitación

La constructora, por su parte, estima que los trabajos de precomisionamiento corresponderían al administrador de los contratos. Su interpretación se funda en la respuesta a una consulta realizada en el proceso de licitación, en que se señala que el "cliente", requerirá al "contratista" de personal calificado para "apoyar" el precomisionamiento. A su juicio, como las definiciones de las BAG establecen que el "contratista" es el administrador, sería, entonces, dicha compañía la encargada de ejecutar los trabajos de precomisionamiento.

Una simple revisión de las consultas y respuestas de la licitación demuestran inequívocamente que la interpretación presentada por la constructora tampoco es correcta. En efecto, lo natural es que en dichos procesos sean ingenieros o profesionales técnicos de la construcción quienes elaboren las preguntas y respuestas que luego se plasman en el documento contractual constituido por aquella misma serie de consultas, los que no siempre están al tanto del contenido normativo de los contratos. Ahora bien, en la licitación era el administrador de los trabajos quien desarrollaba las respuestas a las consultas de los oferentes. Por ello, es razonable estimar y asumir que las partes en esta etapa utilizaron la palabra 'cliente' para denominar al mandante como, asimismo, la palabra 'contratista', para referirse al alcance de los trabajos y obligaciones de la constructora de la planta:

\begin{tabular}{|c|c|l|}
\hline \multirow{2}{*}{2.28.} & Consulta & $\begin{array}{l}\text { Dado que no queda claro lo indicado en punto 7.1 de las Bases Técnicas, favor } \\
\text { definir cuáles de los siguientes servicios pueden ser aportados por el Cliente: } \\
\text { Alimentación, Combustibles, retiro de basura domestica, retiro de Rises, retiro de } \\
\text { Riles, Teléfono, Internet, indicando si son servicios con a sin costo al Contratista. }\end{array}$ \\
\cline { 2 - 3 } & Respuesta & Todos estos servicios son de casto del Contratista. \\
\hline
\end{tabular}

${ }^{35}$ Para definir EPCM, se ha señalado en el ámbito comparado que "EPCM (Ingeniería, Suministros y Administración de la Construcción): significa que la compañía es contratada para proveer la ingeniería, los suministros y servicios de administración de la construcción. Otras compañías son contratadas directamente por el Propietario para encargar la construcción, la que es usualmente administrada por el contratista EPCM en representación del Propietario." Lo señalado es una traducción libre de lo siguiente: "EPCM (Engineering, Procurement and Construction Management): means the company is contracted to provide engineering, procurement and construction management services. Other companies are contracted by the Owner directly to provide construction services and they are usually managed by the EPCM contractor on the Owner's behalf”. Ice-Institution of Civil Engineers (2011), p. 100. En el ámbito nacional, se ha dicho que en esta modalidad contractual "el contratista desarrolla la ingeniería, efectúa suministros y gestiona la construcción por cuenta del propietario, pero no ejecuta directamente las obras Ríos y Molina (2016), p. 62. 


\begin{tabular}{|c|c|l|}
\hline \multirow{2}{*}{2.29.} & $\begin{array}{l}\text { Favor indicar el cuáles son los documentos necesarios para habilitar un Maestro y } \\
\text { un Operador de equipos de levante. Cuál es el plazo de habilitación para trabajara } \\
\text { en las instalaciones del Cliente desde la entrega de los documentos. Además } \\
\text { indicar si esto tiene algún costo para el contratista. }\end{array}$ \\
\cline { 2 - 3 } & Respuesta & $\begin{array}{l}\text { La autorización se otorga durante el día, siempre que toda la documentación } \\
\text { necesaria se hubiese presentado. }\end{array}$ \\
\hline
\end{tabular}

\begin{tabular}{|c|c|l|}
\hline \multirow{2}{*}{ 2.32. } & Consulta & $\begin{array}{l}\text { Indicar si existe factibilidad de agua potable y alcantarillado para las instalaciones } \\
\text { el contratista }\end{array}$ \\
\cline { 2 - 4 } & Respuesta & $\begin{array}{l}\text { Se dispone de alcantarillado y agua potable en el patio de contratistas El } \\
\text { consumo de agua potable serà medido. }\end{array}$ \\
\hline
\end{tabular}

\begin{tabular}{|c|c|l|l|}
\hline \multirow{2}{*}{ 2.32. } & Consulta & $\begin{array}{l}\text { Indicar si existe factibilidad de agua potable y alcantarillado para las instalaciones } \\
\text { el Contratista }\end{array}$ \\
\cline { 2 - 4 } & Respuesta & $\begin{array}{l}\text { Se dispone de alcantarillado y agua potable en el patio de contratistas } \\
\text { consumo de agua potable serà medido. }\end{array}$ \\
\hline
\end{tabular}

\begin{tabular}{|c|c|l|}
\hline \multirow{3}{*}{3.8.} & Consulta & $\begin{array}{l}\text { Cuáles son los contratistas o actividades en las cuales el Contratista del Montaje } \\
\text { Electromecánico tendrá interferencias. }\end{array}$ \\
\cline { 2 - 3 } & Respuesta & $\begin{array}{l}\text { Toda área presentará interferencia (al menos para un } 50 \% \text { de las actividades); se } \\
\text { trata de una planta en operación. }\end{array}$ \\
\hline
\end{tabular}

Lo anterior resulta aún más evidente, tras analizar con detención la consulta y la respuesta a la que la constructora se aferra para argumentar:

Consulta: Indicar responsabilidad del contratista en el precomisionamiento.

Respuesta: El alcance del contrato incluye todos los recursos del contratista, necesarios para alcanzar el término mecánico del proyecto. El contratista deberá prever que el cliente requerirá de personal calificado del contratista, para el apoyo en el precomisionamiento, comisionamientos y PEM de las nuevas instalaciones de la planta.

Como se aprecia de la consulta y respuesta en cuestión, los términos 'cliente' y 'contratista' se repiten. Desde luego, en el mismo sentido que el que se ha explicado anteriormente. La respuesta simplemente reitera el alcance de los trabajos establecidos en la cláusula $3^{\mathrm{a}}$ de los contratos. Adicionalmente, la respuesta también está parafraseando la definición de precomisionamiento dada en las BAG, pues en aquella se señala que para esta labor la constructora debía "emplear personal separado de aquellos dedicados a la ejecución del trabajo". Por eso, la respuesta señala que el mandante exigiría a la constructora personal calificado para dicha labor, y no un mero "apoyo" como lo ha pretendido la constructora como argumento subsidiario.

Finalmente, si la primera parte de la respuesta en análisis indica que es el "contratista" quien debía obtener el término mecánico, es indudable que se está refiriendo a la constructora, pues aquello era uno de los hitos a cumplir para obtener la recepción provisional a la que se refieren las cláusulas 33 de las BAE y BAG. La serie de consultas y respuesta también así lo devela: 


\begin{tabular}{|l|c|l|}
\hline \multirow{2}{*}{26.} & Consulta & $\begin{array}{l}\text { Se solicita confirmar que el término del plazo del contrato (180 dias) corresponde } \\
\text { al término mecánico de la obra. }\end{array}$ \\
\cline { 2 - 3 } & Respuesta & $\begin{array}{l}\text { El término del plazo de 180 dias se considera hasta la emision del certificado de } \\
\text { Recepción Provisional según se especifica en la Cláiusula 33 de las BAE. }\end{array}$ \\
\hline
\end{tabular}

\begin{tabular}{|c|c|l|l|}
\hline \multirow{2}{*}{ 2.23. } & Consulta & $\begin{array}{l}\text { Confirmar que el plazo total del proyecto incluyendo movilización y } \\
\text { desmovilización es de } 180 \text { dias. }\end{array}$ \\
\cline { 2 - 4 } & Respuesta & $\begin{array}{l}\text { El término del plazo de } 180 \text { dias se considera hasta la emision del certificado de } \\
\text { Recepción Provisional según se especifica en la Cláiusula } 33 \text { de las BAE. }\end{array}$ \\
\hline
\end{tabular}

20. La constructora al momento de ofertar reconoció que la tarea de precomisionamiento debía ser ejecutada por ella Luego de los procesos de licitación, la constructora presentó sus ofertas. En aquellas incluyó la programación de los trabajos, considerando expresamente una etapa de pruebas o "precomisionamiento:"

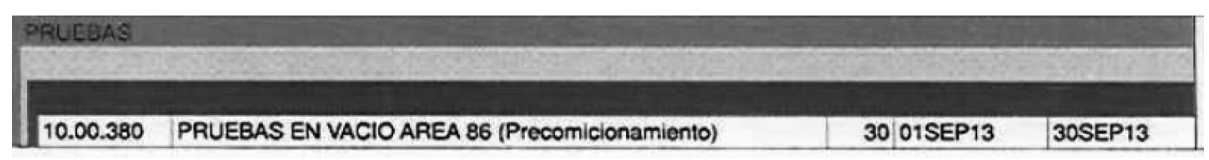

De este modo, desde la época de celebración de los contratos fue previsible para la constructora que el precomisionamiento resultaba una tarea a ejecutar para poder obtener la recepción de las obras. Es más, al incluir expresamente dichos trabajos en su programación -la cual forma parte integrante de los contratos conforme la cláusula 2.1- la constructora se encuentra obligada a cumplir con aquel programa al pie de la letra, pues como se ha señalado en el ámbito comparado en esta materia, el programa de trabajo cobra el estatus de una obligación contractual ${ }^{36}$.

\section{La aplicación práctica de los términos contractuales}

De esta manera, si se estima que las partes emplearon una terminología parcialmente distinta a las definidas en el contrato para 'dueño', 'contratista' y 'subcontratistas', las cláusulas contractuales en que se emplean dichos conceptos deben ser interpretadas -de acuerdo con el inc $3^{\circ}$ del art. 1564 del Código Civil-conforme la aplicación práctica que las partes les dieron, es decir, que al señalar "contratista", aquellas se estaban refiriendo -en la etapa de licitación, al menos- desde luego a la constructora y no al administrador.

\footnotetext{
${ }^{36}$ Se ha señalado que "donde se le ha dado ese estatus [de documento contractual] al Programa, el contratista es obligado a cumplirlo al pie de la letra". Lo anterior es una traducción libre de lo siguiente: "Where a programme is given such a status [a contract document], the contractor is required to comply with it to the letter". KNOwLES (2012), p. 88
} 


\section{El mandante se encuentra habilitado \\ a modificar el alcance de su proyecto}

22. Las partes no discuten realmente acerca de la facultad que tiene el mandante para introducir modificaciones, obras adicionales y extraordinarias al proyecto

Las partes han mantenido controversia respecto de la introducción de modificaciones al proyecto. La constructora señala que aquello produce una "desnaturalización" del contrato. Por su parte, el mandante y el administrador señalan que aquello es una facultad contractual. A nuestro juicio, son estos últimos los que llevan razón.

No obstante su argumentación, la constructora parece también entender lo mismo en su demanda, al señalar que

"las BAG contemplaban la posibilidad de que las obras experimentaran cambios al proyecto original (...), todo dentro del marco de ciertos parámetros y bajo ciertas circunstancias".

Agrega la constructora en su réplica, que el derecho del mandante "a instruir a la Constructora la realización de cambios y la ejecución de nuevas obras, no es controvertido". Dado lo anterior, la pregunta consiste, entonces, en

296 determinar si el empleo de una facultad contractual podría desnaturalizar ${ }^{37}$ al mismo tiempo los contratos.

\section{La introducción de mayores trabajos al proyecto}

no desnaturalizan contratos a precios unitarios como los pactados

En el derecho inglés se ha señalado no existir una definición generalmente aceptada respecto del término "obra extraordinaria". Sin embargo, se le ha definido como aquel trabajo "no expresamente ni implícitamente incluido en el diseño del proyecto" ${ }^{38}$. Se dice que dicha definición resulta más adecuada para los contratos de construcción a suma alzada ${ }^{39}$, por cuanto en aquellos el programa y el proyecto se encuentran prácticamente definidos en su totalidad,

${ }^{37}$ De acuerdo con el Diccionario de lengua española, desnaturalizar implica alterar las propiedades o condiciones de algo. Disponible en http://dle.rae.es/srv/search?m=30\&w=desnaturalizar. [fecha de consulta: 15 de diciembre de 2017].

${ }^{38}$ Furst et al. (2006), p. 116.

${ }^{39}$ Como ha señalado Prado, p. 767, bajo esta modalidad, el constructor, contratista o empresario, dirige, ejecuta y administra la obra hasta su total terminación por un precio cierto, global y único aportando el trabajo y los materiales. El precio convenido con el mandante o comitente o con el propietario del terreno que encomienda la ejecución de la obra, se mantendrá invariable o inamovible salvo que se establezca una cláusula de revisión de precios o que se introduzcan obras extraordinarias o bien reformas o modificaciones introducidas en el proyecto por el comitente que impliquen un aumento o disminución de la obra, en cuyo caso la estipulación del precio inalterable pierde su fuerza obligatoria y debe ser renegociada. 
de forma que el constructor cubica las obras y luego oferta el precio y el plazo conforme a la cantidad de trabajos previamente establecidos.

Sin embargo, de acuerdo con las cláusulas en que se fijó el precio de los contratos, el valor de la construcción se fijó "a serie de precios unitarios". En esta clase de contratos es usualmente irrelevante la introducción de uno u otro trabajo adicional, puesto que el contratista tiene derecho a ser pagado de acuerdo con la avaluación de la partida construida en la serie de precios ofertados o, en su defecto, a un precio de mercado y razonable ${ }^{40}$. Es decir, en este tipo de contrato, por su propia naturaleza, el mandante introducirá e instruirá trabajos después de iniciada la construcción. Mal que mal, según asentamos, en los contratos fast track-que normalmente se pactan a serie de precios unitarios- la ingeniería aún se encuentra en desarrollo durante la ejecución de las obras, de modo que la incorporación de una u otra partida resulta normal y previsible.

24. Las partes definieron contractualmente y en términos amplios, la posibilidad de introducir modificaciones al proyecto. Posibles problemas en su determinación y formalización

Basta recurrir a las cláusulas $23^{\mathrm{a}}$ y $24^{\mathrm{a}}$ de las $\mathrm{BAG}$, para dar cuenta que para la constructora resultaba previsible y esperable que el mandante introdujera modificaciones al proyecto que tendría que ejecutar. En efecto, la cláusula $23^{\mathrm{a}}$ de las BAG señala que los trabajos extraordinarios se incorporarán al contrato mediante una modificación del mismo. Luego, la cláusula $24^{\text {a }}$ de las BAG indica que el administrador podrá dar instrucciones a la constructora

"para efectuar cambios, consistentes en adiciones, supresiones u otras revisiones de las obras, trabajo o servicios contemplados en el alcance del Contrato, y que pueden o no afectar el precio, plazo y/o calidad del mismo, sin perjuicio de las compensaciones que sean procedente de acuerdo a lo establecido en esta cláusula".

La cláusula 21.4 de las BAG, define un mecanismo contractual para formalizar los cambios de los servicios, trabajos y obras. Finalmente, la cláusula $25^{\mathrm{a}}$ de las BAG estableció una modalidad de compensación por modificaciones al proyecto.

En experiencia de estos informantes, no obstante las disposiciones contractuales, lo cierto es que en la industria de la construcción la introducción de obras adicionales, extraordinarias o modificaciones de obras, normalmente desemboca en un conflicto entre el mandante y el contratista respecto de si

${ }^{40}$ Lo anterior, siguiendo la opinión sostenida en derecho comparado: "In a measurement and value contracts it is usually immaterial whether any particular item of work that a contractor has to do is in the contractor not, because the contractor is entitled to be paid for it at the contract rate if it is applicable, or at a reasonable price if it is not”. FURST et al. (2006), p. 121. 
el trabajo encomendado era o no una obra adicional; el modo en que formalmente aquel trabajo debía ser instruido al constructor; el mecanismo para determinar una ampliación de plazo y un aumento del precio por la ejecución del mismo, entre tantas otras divergencias. En terreno, es usual que muchas cosas se aparten de la letra expresa del contrato debido a lo vertiginoso del proceso de construcción.

Desde un punto de vista jurídico, ante situaciones como la anterior se podrían sugerir las siguientes pautas de resolución:

a) Seguir los requisitos y condiciones establecidos por el contrato, para efectos de determinar la procedencia de la obra extraordinaria, la cuantía de su pago y la posible extensión de plazo.

b) Entender -de acuerdo con la prueba rendida en juicio- modificado expresa o tácitamente el procedimiento convencional pactado por las partes, siempre y cuando el contrato lo permita ${ }^{41}$.

\section{LOS REMEDIOS AL INCUMPLIMIENTO CONTRACTUAL}

\section{A. Las multas contractuales}

\section{Las multas contractuales revisten la naturaleza}

298 de una cláusula penal

No obstante que las cláusulas $31^{\mathrm{a}}$ de las BAE y de las BAG denominen como "multas" a la sanción aplicable ante cierta clase de incumplimientos contractuales, ellas no son más que el establecimiento de cláusulas penales, pues se tratan de convenciones por las que un contratante asegura el cumplimiento de una obligación -de acuerdo con el art. 1535 del Código Civil- mediante la sujeción a una pena que consiste en dar algo en caso de no ejecutar o de retardar una obligación contractual. No habiendo normativa especial que regule la cuestión en comento, las cláusulas $31^{\mathrm{a}}$ de las $\mathrm{BAE}$ y de las $\mathrm{BAG}$ se rigen por las normas del derecho civil y, en especial, por aquellas contempladas en el título xI del libro IV del Código Civil.

${ }^{41}$ Por ejemplo, en los casos que las partes han acordado una cláusula de las conocidas en derecho anglosajón como No-Oral or Written Modification Clauses, en las que los contratantes establecen que la voluntad plasmada en el contrato es y será la única voluntad que debe gobernar su actuar. Sobre este tipo de cláusula, la Corte de Apelaciones de Santiago sentenció: "8) Que de la lectura de la cláusula referida, aparece que las partes declararon, en forma expresa, que este es el único instrumento que los rige y que cualquier modificación a las materias en las que se han convenido, requiere que exista un acuerdo por escrito. $9^{\circ}$ ) Que entonces es este el marco fijado expresamente por los contratantes, conforme al principio de autonomía de la voluntad en que debía desarrollarse y ejecutarse el instrumento celebrado por éstas y conforme al cual debe analizarse la controversia planteada en este juicio. $10^{\circ}$ ) Que en estas condiciones y de acuerdo con lo expresamente convenido por las partes de autos, no resulta procedente que se establezca- como lo pretende el actor- que, el contrato haya sido modificado y que su vigencia se haya ampliado de uno a cuatro años”. Davis Autos S.A. con General Motors Chile (2013-2014). 
En este escenario, las partes acordaron una cláusula penal ante el incumplimiento de ciertos plazos para la ejecución de las obras, cobrando aplicación una multa diaria de acuerdo con la tabla establecida en la cláusula $31^{\text {a }}$ de las BAE. Es decir, se pactó una pena de carácter moratoria, aquella que se prevé para el caso de retardo en el cumplimiento, y con la cual se entiende reparar los perjuicios provenientes de la mora del deudor. Adicionalmente, los contratos establecieron multas de carácter compensatorio ${ }^{42}$ para avaluar anticipadamente perjuicios derivados de incumplimientos a "compromisos administrativos, de seguridad o calidad, o por retiro del personal clave". Es decir, para avaluar anticipadamente perjuicios derivados de incumplimientos distintos de aquellos relativos al retraso en la ejecución de los trabajos.

26. Las cláusulas penales son exigibles luego de acaecido un incumplimiento contractual

Para la procedencia del cobro de la cláusula penal, tradicionalmente se han exigido los mismos requisitos que para la indemnización de perjuicios ordinaria, excluyendo la acreditación de la existencia y el monto de los daños reales y su causalidad $^{43}$. Sin embargo, la obligación asumida por la constructora es una de aquellas de resultado, de modo que no es posible para esta alegar simplemente la ausencia de culpa para excusar su incumplimiento; bastando aquel hecho para hacer efectiva la pena.

Entonces, para enervar el cobro de las cláusulas penales o multas pactadas, deberá la constructora acreditar que ha cumplido sus "compromisos administrativos" y su obligación de entregar las obras de forma correcta, completa y oportuna o, en su defecto, el acaecimiento de un caso fortuito. Desde luego, de conformidad con los arts. 1698 y 1547 del Código Civil, la prueba del incumplimiento no puede serle exigida a quien hace uso de la cláusula penal, pues aquello implicaría someterlo a la prueba de un hecho negativo, que, incluso, ante la pasividad del deudor haría ver afectada su pretensión. Es el deudor quien debe acreditar el cumplimiento oportuno y exacto de su obligación de acuerdo con las reglas del pago, en especial aquella del art. 1569 del Código Civil. Así lo enseñaba tempranamente el profesor René Abeliuk ${ }^{44}$.

${ }^{42}$ Corral (2012), p. 174.

${ }^{43}$ Op. cit., p. 173.

${ }^{44}$ Abeliuk (2014), p. 926, enseña: "de acuerdo al artículo 1698, corresponde probar la obligación o su extinción al que alega aquella o ésta. En consecuencia, si al acreedor le corresponde acreditar la existencia de la obligación, no le toca en cambio, probar el incumplimiento. Es el deudor quien debe establecer que ha cumplido, porque alega el pago, o sea la extinción de la obligación y sobre él coloca la ley la carga de la prueba en tal caso". Actualmente, CorraL, p. 177, también señala: "no se exige la prueba del incumplimiento cuando el acreedor demanda la ejecución forzada, la indemnización de perjuicios o la resolución del contrato. En todos estos casos, basta que el acreedor aduzca que la obligación no ha sido cumplida para que su acción se considere procedente, salvo que el deudor se excepciones y pruebe el pago. Sobre esta lógica opera la norma general de la carga de la prueba del art. $1698 \mathrm{CC}$ : el acreedor debe probar la existencia de la obligación, el deudor su extinción (por el cumplimiento o pago efectivo)”. 
27. La obligación penal se extingue conforme a las reglas generales

Al tratarse las multas contractuales de verdaderas cláusulas penales, la extinción de las obligaciones que de aquellas emanan se rigen por las reglas generales de las obligaciones, ya sea de manera principal o consecuencial.

Sin embargo, la constructora argumenta en juicio que el cobro de las cláusulas penales sería improcedente por ser esto "extemporáneo" y "reactivo". De acuerdo con sus términos, pareciese que la constructora pretende la aplicación de la caducidad como un modo de extinguir la obligación penal, empero, estimamos que aquella institución no tiene cabida por su carácter excepcional en materia civil, dado que no existe norma legal ni convencional que la establezca para este caso particular en favor de la constructora. Indudablemente, en aquellos términos, el transcurso del tiempo como forma de extinguir las obligaciones solo podría operar de acuerdo con las reglas de la prescripción, lo que no ha acontecido ${ }^{45}$.

Estos informantes tampoco estiman que exista renuncia o remisión de la obligación penal. Habrá propiamente renuncia, cuando el acreedor -conforme el art. 12 del Código Civil- libera al deudor de la pena antes de que haya incurrido en ella. A pesar de ser un acto no sujeto a solemnidades, es el deudor quien debe acreditar el hecho de haberse despojado el acreedor de aquel derecho. Ahora, si la cláusula penal ya se ha hecho exigible -como parece tratarse el caso- se deben aplicar las reglas de la condonación de el art. 1652 y siguientes del Código Civill ${ }^{46}$, cuestión que de los antecedentes tenidos a la vista no se desprende que haya ocurrido.

En fin, la constructora argumenta que al no haber sido aplicada las multas en los estados de pago, aquellas ahora no tendrían cabida. No obstante, considera este informante que las cláusulas $31^{\mathrm{a}}$ de las BAE y de las BAG establecen una facultad del mandante y del administrador, y no una prerrogativa que debiese ser aplicada de forma imperativa bajo sanción de caducidad. Por ello, no basta la mera pasividad de estos últimos para que se presuma su voluntad de remitir la deuda que la constructora contrajo tras incumplir los contratos.

Siendo vigentes y actualmente exigibles las penas establecidas contractualmente por las partes, tanto el mandante como el administrador disponen de la facultad para hacer efectivos esos cobros a través del procedimiento arbitral.

\section{B. Backcharges o cargos al subcontratista}

28. Los backcharges son un mecanismo contractual destinado a resguardar el interés contractual del mandante

Debido a la contratación internacional y a la llegada de la inversión extranjera, en nuestro país la práctica forense del Common Law ha tomado un importan-

${ }^{45}$ Abeliuk (2014), pp. 1406-1408.

${ }^{46}$ Corral (2012), p. 328. 
te papel en el proceso de negociación y redacción de contratos. En efecto, cada vez es más usual encontrarnos con instrumentos sumamente extensos y complejos, en que las partes establecen minuciosamente sus derechos y obligaciones, definen expresamente conceptos, regulan las consecuencias de los incumplimientos y los remedios a los mismos, entre tantos otros acuerdos que quedan plasmados en el mismo documento. Lo anterior se explica por cuanto en el derecho anglosajón -y en muchos casos también debido a nuestras anquilosadas reglas de derecho civil- muchas circunstancias del negocio jurídico no se encuentran reguladas de manera íntegra, de modo que los contratantes se ven obligados a tomar un actitud más activa en la elaboración de acuerdos estableciendo sistemas autocompositivos para resolver sus controversias superando las ineficiencias económicas aparejadas.

En aquel contexto surge la cláusula $21^{\text {a }}$ de las BAG, en que se establece la facultad del administrador --en representación del mandante- para "corregir o subsanar las deficiencias o incumplimientos respecto de la obra, trabajo o servicio, o para que reponga materiales perdidos o dañados". Esta medida correctiva tendría lugar si la constructora demostraba inhabilidad o falta de voluntad para realizarla por sí misma; caso en el cual se cargarían los costos de reparación o reconstrucción a la constructora, a través de compensaciones con pagos que le fueran adeudadas, sin perjuicio de poder ser obtenidos a través de otros remedios contractuales establecidos en los contratos ${ }^{47}$.

29. Los backcharges disponen la naturaleza jurídica de cumplimiento de la prestación comprometida en los contratos

Atendido el objeto de la medida correctiva, se desprende que aquella busca, dentro de los plazos de ejecución de los trabajos pactados, garantizar la obtención de la misma prestación establecida en los contratos. Lo que debe observarse es que mediante los backcharges, el mandante obtendrá el cumplimiento en naturaleza de la ejecución de las obras, conforme las especificaciones técnicas de los contratos, pero ya no por la misma constructora, sino por un tercero, sea este el administrador $\mathrm{u}$ otro contratista. No se trata, entonces, de aquella indemnización de perjuicios que le asiste al acreedor para demandar los daños que superan el valor de la prestación incumplida, pues los backcharges no son una nueva obligación contractual, diferente e independiente de aquella infringida. La obligación de construcción se mantiene, pero cambia el mecanismo para satisfacerla, cuestión que es también conocida en doctrina como una "operación de reemplazo" 48 .

Lo anterior, por ejemplo, es claro en materia de contratos en derecho estadounidense. En efecto, el Common Law y más actualmente la sección 2-712 del

\footnotetext{
${ }^{47}$ Como hacer efectivas las boletas de garantía de fiel cumplimiento de los contratos.

${ }^{48}$ A través de la operación de reemplazo, "el contratante insatisfecho logra satisface in natura su interés en el cumplimiento del contrato, no por la vía del cumplimiento del otro contratante, sino a través de un tercero (vía alternativa), pero con cargo al otro contratante”. MoRALES (2014), p. 99
} 
$U C C$, contemplan la institución denominada COVER para referirse al derecho que tiene el comprador -frente al incumplimiento del vendedor- para salir al mercado a adquirir las mercaderías de reemplazo que no fueron entregadas por el vendedor ${ }^{49}$. La regla supone, entonces, que el comprador ha debido salir a adquirir bienes en el mercado a un precio superior que aquel convenido inicialmente con el vendedor. Es por esa razón que la norma dispone el derecho del comprador a obtener del vendedor la indemnización de los perjuicios representados por el mayor valor que el comprador ha debido pagar por la adquisición efectuada al tercero ${ }^{50}$. Nótese -entonces- que la indemnización de perjuicios está constituida no por la prestación de reemplazo, sino por la diferencia de valor que el comprador ha debido pagar al tercero por sobre el precio convenido con el vendedor. Como es lógico no se incluye la prestación misma, pues ella ha sido obtenida del tercero como cumplimiento en naturaleza.

Comprender lo anterior resulta de extraordinaria relevancia, atendidas las diferencias en cuanto a los requisitos de procedencia del cumplimiento en naturaleza (sea o no forzado) en relación con la indemnización de perjuicios. Dicha diferencia se encuentra determinada en cuanto la culpabilidad no constituye condición necesaria para obtener la prestación in natura, pero sí para obtener una indemnización de perjuicios. Así, el profesor Daniel Peñailillo sostiene:

"producido el incumplimiento (en cualquiera de sus formas), como hipótesis general, el acreedor puede demandar cumplimiento en especie, aun forzadamente. Para tal efecto solo se requiere la infracción del contrato; y, ciertamente, no se requiere de culpa. El fundamento de la pretensión está en el incumplimiento contractual (...). Se ha dicho que para pedir el cumplimiento en especie no se requiere de culpa, que basta la infracción del contrato y que el fundamento de la pretensión está en el incumplimiento contractual; más al fondo, el fundamento es la obligatoriedad del contrato que ahora ha sido infringido, Se pide la ejecución de la prestación simplemente porque a eso se obligó el deudor. En tal eventualidad, es

${ }^{49}$ La letra "A" de la sección 2-712 del $U C C$, señala: "después de un incumplimiento contractual (conforme a la sección precedente) el comprador puede cubrirse, haciendo de buena fe y sin demora irrazonable, cualquier compra razonable de o contrato para comprar mercaderías en reemplazo de aquellas debidas por el vendedor". El texto anterior, es una traducción libre de lo siguiente: "After a breach within the preceding section, the buyer may "cover" by making in good faith and without unreasonable delay any reasonable purchase of or contract to purchase goods in substitution for those due from the seller".

${ }^{50}$ La letra "B" de la sección 2-712 del UCC, señala: "el comprador puede recuperar del vendedor como indemnización de perjuicios, la diferencia entre el costo de cubrirse y el precio del contrato, junto con cualquier otro daño incidental o consecuencial como de aquí en adelante es definido (Sección 2-715) pero menos los costos ahorrados como consecuencia del incumplimiento del vendedor." El texto anterior, es una traducción libre de lo siguiente: “(B) The buyer may recover from the seller as damages the difference between the cost of cover and the contract price together with any incidental or consequential damages as defined (Section 2-712) but less expenses saved in consequence of the seller's breach". 
evidente que la culpa no tiene intervención; producido el incumplimiento, no se divisa razón para exigir un nuevo requisito más allá del contrato, a fin de que el acreedor pueda demandar la prestación convenida" ${ }^{51}$.

Como es lógico, si la culpabilidad no es requisito para la obtención del cumplimiento en naturaleza obtenido mediante una operación de reemplazo, entonces tampoco diligencia puede constituir justificación o excusa. De esta manera, aplicado lo anterior al caso que se informa resulta indudable que la constructora no puede alegar ausencia de culpa para excusar responder por el cumplimiento alternativo de su prestación. En efecto, requerir aparte del contrato incumplido la culpa de la constructora significaría exigir un nuevo (entonces doblado) fundamento para la pretensión de cumplimiento en naturaleza. En otras palabras, si para exigir lo que reza el contrato se requiere, además, la culpa del deudor, ca qué obliga el contrato, si por sí mismo no basta para exigir lo estipulado en aquel? ${ }^{52}$.

Lo cierto es que los backcharges disponen la naturaleza propia de cumplimiento y no de resarcimiento. Para su procedencia no debe establecerse la existencia de culpabilidad ni puede admitirse como excusa la debida diligencia, pues dicha regulación -así como las posibles agravantes o limitaciones- resulta inaplicable. Basta que la constructora haya incumplido los contratos para que este remedio contractual cobre aplicación, pues el derecho a la pretensión específica supone exclusivamente que el deudor no haya ejecutado su obligación o lo haya hecho en forma imperfecta.

\section{Garantías a la construcción de las obras.}

30. Tras la ejecución de las obras, la constructora debe garantizar que la satisfacción del interés contractual del mandante se mantenga

Dijimos que mediante los backcharges establecidos en la cláusula $21^{\text {a }}$ de las BAG, se lograba obtener el cumplimiento de la misma prestación contractual incumplida por la constructora durante la ejecución de las obras. Una vez entregadas parcial o totalmente, el campo de aplicación de la cláusula $21^{\text {a }}$ de las BAG cede ante los efectos de la cláusula $29^{\mathrm{a}}$-tanto de las BAE como de las BAG- la que establece una obligación de "garantía de calidad" del cumplimiento, hasta por doce meses luego de ser recepcionados provisionalmente los trabajos.

De acuerdo con las señaladas cláusulas, la constructora contrajo una obligación de carácter doble ${ }^{53}$. La primera, relativa a "reparar y/o rehacer" los

${ }^{51}$ Peñailillo (2008), p. 334.

${ }^{52}$ Op. cit., p. 337. En sentido similar, Barros (2007), p. 415, enseña: "para pedir el cumplimiento en naturaleza, sea que esté dirigida a la prestación contractual por el propio deudor o devenga en una obligación de valor en dinero, no tiene más requisito que se tenga por acreditado el hecho del incumplimiento".

${ }^{53}$ Señala la cláusula $29^{\text {a }}$ de las BAG: "Estas responsabilidades significan la obligación del Subcontratista de reparar y/o rehacer los trabajos defectuosos, como asimismo de indemnizar por los daños y perjuicios causados por incumplimiento de la calidad, omisión, o incorrecta ejecución”. 
trabajos que se encontraran defectuosos o se manifiesten en aquellos fallas por faltas al diseño, a los materiales, a la mano de obra o servicios. La segunda, una obligación de "indemnizar los perjuicios" causados por el incumplimiento de la calidad o incorrecta ejecución de las obras. Finalmente, los trabajos de reparación o reejecución podían ser realizados por el mandante, si la constructora no lo hacía o si, en definitiva, se perdía la confianza en el contratista debido a la gravedad de la deficiencia detectada.

En el derecho comparado, se ha explicado que este tipo de cláusulas contractuales son usuales en la industria de la construcción. En ellas se establece:

"el contratista deberá subsanar defectos, reparar o hacer mantención a los trabajos por cierto lapso de tiempo luego de la terminación de los mismos. Este período de tiempo es a veces conocido como periodo de responsabilidad por defectos o periodo de mantención" ${ }^{54}$.

Asimismo, se ha establecido que dentro de aquel término el

"mandante tiene el derecho a reclamar del contratista que desatiende o se niega a subsanar los defectos en los trabajos, los costos provenientes de tener que encomendar aquellos trabajos a terceros" $" 55$.

En el ámbito nacional se ha dicho que la garantía contenida en estas cláusulas "se refiere a los daños, errores, insuficiencias o defectos que experimente la obra una vez recepcionada la misma" 56 .

31. Tal como ocurre con los backcharges, la cláusula de calidad resguarda el cumplimiento de la obligación en naturaleza.

Alternativamente, resguarda el reclamo a la indemnización de daños

La cláusula de "garantía de calidad" establece al cumplimiento en naturaleza y a la indemnización de perjuicios como remedios al incumplimiento contractual. En primer lugar, el "reparar y/o rehacer" significa para el mandante la obtención misma de la prestación de la constructora (la construcción), sea que provenga de la misma o de un tercero. $\mathrm{Al}$ agregarse la indemnización, aquello implica, adicionalmente el derecho del mandante a obtener otros daños consecuenciales y extrínsecos del incumplimiento de la obligación de entregar la construcción sin fallas ni defectos.

${ }^{54}$ Lo citado, es una traducción libre del siguiente pasaje: "There is frequently a clause in building contracts that provides that the contractor shall make good defects, or repair or maintain the works for a certain period after completion. This period is sometimes referred to as the defects liability period or maintenance period". FuRsT et al. (2006), p. 338.

${ }^{55}$ La cita es una traducción libre de lo siguiente: "An employer in entitled to claims from a contractor who neglects or refuses to make good defects in the work the costs arising from having others undertake the work". KNowles (2012), p. 324.

${ }^{56}$ Ríos y Molina (2016), p. 265. 
Interesa asentar que, de acuerdo con los contratos, la obligación de reparar y/o rehacer las obras puede ser sometida -al igual que en el caso de los backcharges- a una operación de reemplazo. En ese caso, el mandante ante el incumplimiento de la constructora, puede obtener la satisfacción in natura. Esto no solo proviene de la letra de los contratos, sino, también, de lo dispuesto en el art. 1553 del Código Civil, norma que disciplina precisamente a las obligaciones de hacer y que reconoce la facultad del acreedor para optar, según más le convenga a sus intereses, entre la ejecución forzada por el mismo deudor o el cumplimiento por un tercero, pero en este último caso con cargo al mismo deudor. Sea cual fuere la opción tomada, puede el acreedor solicitar la indemnización de daños proveniente de la mora del deudor ${ }^{57}$.

En definitiva, la vinculación contractual entre el mandante y la constructora debe ser entendida como garantía de un resultado, lo que impone en la constructora el deber de satisfacer el interés contractual del mandante. Dentro de aquel, encontramos la entrega de los trabajos libre de defectos y fallas; cumplimiento en naturaleza que el contrato y nuestro Código Civil habilitan a obtener de la constructora o de un tercero, pero a costa de la primera.

32. El mandante tiene derecho a exigir los costos pagados a terceros para reparar y/o rehacer los trabajos de montaje de cañerías

El mandante estima que la constructora debe reembolsarle los costos pagados por trabajos de reparación de defectos en el montaje de cañerías, los que se manifestaron luego de que la constructora hiciera entrega de aquellas partidas. Por su parte, la constructora no controvierte la procedencia de la cláusula de "garantía de calidad", sino que introduce al proceso una serie de hechos que la exculparían de cualquier tipo de responsabilidad en las fallas detectadas en las cañerías.

Sin entrar a analizar cuestiones de hecho, estimamos que si el montaje de cañería era parte de la obligación contractual de la constructora, resulta evidente que aquel trabajo debía ser entregado al mandante libre de defectos. En caso contrario, el mandante dispone de los remedios contractuales que los contratos le otorgan, entre ellos, la posibilidad de contratar a terceros para ejecutar -con cargo a la constructora- las reparaciones a las obras hasta obtener los parámetros constructivos acordados por las partes.

Sin embargo, creemos que dentro de los costos a ser reembolsados por la constructora al mandante, no deben considerarse los pagos realizados a consultores o expertos para determinar los defectos ${ }^{58}$, pues es precisamente el mandante quien debía acreditar dicha circunstancia para que la cláusula de "garantía de calidad" operara en su favor ${ }^{59}$.

${ }^{57}$ Bahamondes (2011), p. 248.

${ }^{58}$ En el derecho anglosajón, producto del caso Johnson v. WH Brown Construction (Dundee) Ltd (2000), también se ha establecido lo mismo: "the employer would not be entitled to recover the costs incurred in paying a consultant to demostrate that the work was defective". KNOWLES (2012), p. 324.

${ }^{59} \mathrm{En}$ efecto, la constructora en caso de rebatir dicha determinación técnica, también debería incurrir en costos de expertos o peritos. 


\section{La indemnización de daños: límites a la responsabilidad civil de las partes}

\section{Los contratos establecen cláusulas agravantes}

y limitativas de responsabilidad

Las partes mantienen controversia respecto de la aplicación o no de cláusulas contractuales que vendrían a modificar el régimen legal y supletorio de responsabilidad civil al que se encuentran sujetas. Las partes no discuten sobre su validez o ineficacia.

Conforme a los incisos finales de los arts, 1547 y 1558 del Código Civil, nuestra doctrina ha distinguido tres tipos distintos cláusulas modificatorias de responsabilidad civil: aquellas en que los contratantes pactan una limitación, aquellas en que agravan la responsabilidad o aquellas en que la exoneran ${ }^{60}$. En opinión de estos informantes, los contratos contienen claramente al menos dos de aquellas: agravantes y limitativas.

Las cláusulas que agravan la responsabilidad del deudor son, por ejemplo, las que lo hacen responder de un grado mayor de culpa (de leve a levísima), o por el caso fortuito (como en el caso del art. 1673 del Código Civil), o por perjuicios por los cuales normalmente no respondería (como los imprevistos). Manifestaciones de esto se desprenden inequívocamente, entre otras, del literal e) de la cláusula $26^{\text {a }}$ de las BAG y de la letra a) de la cláusula 27.1 de las BAG. 306 En ambos casos, y no obstante encontrarnos ante un contrato bilateral ${ }^{61}$, la constructora comprometió emplear la suma diligencia o cuidado en el cumplimiento de sus obligaciones, lo que conforme el art. 44 del Código Civil, implica responder de culpa levísima. Esto no se contrapone con lo dicho respecto de las obligaciones de resultado del constructor, pues es una manera de enfatizar el estándar de cuidado que la constructora debía observar al emplear lo denominado en doctrina como "diligencia promotora" ${ }^{2}$, pues junto con sus obligaciones de entregar la planta dentro de plazo y correctamente ejecutada, la constructora debía adoptar para cumplir con su prestación una serie de medidas concretas para la superación de obstáculos o impedimentos que pudieran afectar el fiel desarrollo de su obligación, fueran estos previsibles o no.

Pero los contratos también establecen cláusulas limitativas de responsabilidad en las cláusulas $31^{\mathrm{a}}$ y $37^{\mathrm{a}}$ de las BAG y de las BAE, respecto del monto y la naturaleza de los perjuicios que podrán ser demandados ante el incumplimiento de la contraparte. Las primeras cláusulas limitan al 10\% del

${ }^{60}$ En esta materia, véase GonZÁLEZ (2011), pp. 89-100 y Acosta (1998), pp. 249- 276.

${ }^{61}$ Debe recordarse que el art. 1547 del Código Civil, recoge la denominada prestación de culpas, en conformidad a la cual el deudor responde de culpa leve, levísima o lata, según la utilidad que le reporte el contrato a las partes. Es decir, la regla citada contempla distintos grados de diligencia exigibles al deudor para evaluar si satisfizo o no la obligación comprometida. En el caso de los contratos bilaterales, en que se reporta una doble utilidad por las partes, lo normal es que el deudor responda de culpa leve.

${ }^{62}$ Véase Vidal (2007), pp. 41-59. 
valor de los contratos, la cuantía de la cláusula penal o multa que se devengue por concepto de atrasos en la entrega de los trabajos. Las segundas cláusulas denominadas "exclusión de daños consecuenciales", establecen una supresión o renuncia de diversos daños a ser demandados (entre otros, el lucro cesante y el daño moral).

34. Las cláusulas limitativas de responsabilidad solo tienen por objetivo fijar la naturaleza y el monto máximo de los perjuicios a ser indemnizados por las partes

En opinión de estos informantes, no resulta complejo observar que estas cláusulas de responsabilidad limitada solo se refieren $-\mathrm{y}$, en consecuencia, limitan su aplicación- a la indemnización de perjuicios como remedio frente al incumplimiento. Los contratos -y en especial las BAE y las BAG- al limitar la responsabilidad, lo están haciendo en un sentido estricto, que se identifica con la indemnización de perjuicios, pero nunca en un sentido amplio, sinónimo del ejercicio de la totalidad de los remedios de que pueda disponer el acreedor ante el incumplimiento ${ }^{63}$.

Como ya lo hemos señalado, sostener lo contrario implicaría confundir la indemnización de perjuicios con el cumplimiento en naturaleza de la obligación.

De este modo, el acreedor debe sujetarse a los efectos de una cláusula de limitación de responsabilidad en los términos pactados en los contratos, solo en lo que tiene relación con la indemnización de perjuicios, pero no en lo que concierne a otros remedios legales o contractuales, tales como el cumplimiento forzado -y sus homólogos backcharges y la cláusula de "garantía de calidad"- o la resolución del contrato. Dichos remedios al incumplimiento no se ven afectados ni en su monto ni en su naturaleza, pues las partes solo han pretendido excluir perjuicios con carácter "consecuencial" al incumplimiento mismo de la prestación, pero no limitar la entrega de lo que rezan los contratos. Indudablemente, aplicar cláusulas limitativa de responsabilidad civil al cumplimiento forzado de la obligación constituiría un grave error jurídico.

35. La interpretación de la constructora respecto de los derechos de la "parte afectada", no encuentran asidero en las cláusulas limitativas de responsabilidad establecidas en los contratos

De acuerdo con la constructora, es exclusivamente la cláusula $37^{\mathrm{a}}$ de las BAE la que regularía la forma en que se ha dispuesto la limitación de responsabilidad. Adicionalmente, indica que la misma cláusula contemplaría una excepción:

"que la parte afectada podrá oponer las acciones judiciales que corresponda a fin de que se le indemnicen los perjuicios que allí se excluyen,

${ }^{63}$ Pantaleón (1995), p. 3922. 
lo que ocurrirá siempre que aquella parte que incumpla el contrato lo haga con negligencia, culpa, dolo o conducta ilegal”.

A nuestro juicio, dicha interpretación es incorrecta. En primer término, porque la cláusula 37 de las BAE señala expresamente en su primera parte: "El subcontratista, deberá dar cumplimiento a lo establecido en la cláusula 37 de las BAG”. Ya explicamos que, salvo en el periodo de licitación -y así también lo señaló la constructora transversalmente durante la etapa de discusión del arbitraje- el término 'subcontratista' se refiere a la constructora. Luego, la cláusula 37 de las BAG señala:

"en consecuencia, en este acto el subcontratista y sus representantes, renuncian expresamente a los derechos y acciones que por este concepto pudieren ejercer. El Contratista [administrador] y el Propietario [mandante] tendrán derecho de ejecutar las acciones que por este concepto pudieren ejercer, si la otra parte (Subcontratista [constructora] y sus representantes y sus terceros) ha cometido negligencia, culpa, dolo o conducta ilegal".

Como puede observarse, las BAG indican en forma expresa que la excepción a la limitación de responsabilidad aplica solo para el administrador y el mandante, pero no para la constructora.

Si bien el texto de las BAE es desafortunado, no debe perderse de vista que su redacción es prácticamente idéntica a la de las BAG, y que ella no pretende conferir este derecho al subcontratista, sino a la "parte afectada". Ahora bien, de su lectura conjunta, el término "parte afectada" que se señala en las BAE, se realiza en aquella parte en que las BAG se están refiriendo al administrador y al mandante, pues la constructora renunció en las BAG a la pretensión indemnizatoria, siendo solo los primeros quienes podrían sortear la cláusula limitativa de responsabilidad, y demandar por "negligencia, culpa, dolo o conducta ilegal" de la constructora. Lo anterior, nos parece, es la mejor interpretación que puede dársele al término "parte afectada" de acuerdo con lo dispuesto por el art. 1564 del Código Civil.

36. Límites a la aplicación de las cláusulas modificatorias de responsabilidad

La cláusula de "exclusión de daños consecuenciales", que viene a limitar la naturaleza de los daños a indemnizar, establecen expresamente que resulta válida mientras los contratantes no actúen con dolo, fraude o culpa grave. Aquello no es más que una concreción de lo sostenido en doctrina ${ }^{64}$ y lo fallado por

\footnotetext{
${ }^{64}$ Barros (2006), p. 1098.
} 
nuestra jurisprudencia ${ }^{65}$ en la materia, pues no puede ser pactado de antemano la irresponsabilidad de una de las partes en caso de un actuar malicioso o con culpa grave ${ }^{66}$, dado que ello significaría condonar el dolo futuro prohibido por el art. 1465 del Código Civil.

Por ello es que a pesar de que las BAE y las BAG señalen que un actuar "negligente o culposo" bastaría para invalidar la limitación de responsabilidad pactada, estos informantes estiman que dicha interpretación es errada en atención a la regulación normativa que han construido los autores y los máximos tribunales de justicia respecto del uso que este tipo de cláusula tiene en el tráfico jurídico. Lo usual es que los contratantes limiten o excluyan su responsabilidad civil por actos meramente culposos, y que sea solo ante actuaciones maliciosas que las reglas generales establecidas en el Código Civil cobren aplicación.

La correcta interpretación de la cláusula contractual debe realizarse a la luz del art. 1562 del Código Civil, pues, de bastar la mera negligencia para excluir la aplicación de la cláusula limitativa de responsabilidad, en la práctica se le estaría dejando sin efecto y el "sentido en que una cláusula puede producir algún efecto, deberá preferirse a aquel en que no sea capaz de producir efecto alguno".

\section{E. La terminación del contrato.}

37. El ejercicio de la acción resolutoria es un derecho potestativo del acreedor

La cláusula $38^{\mathrm{a}}$ de las $\mathrm{BAG}$, establece diversas hipótesis en que las partes quedaron habilitadas para pedir la terminación o resolución de los contratos. Sobre el particular, la constructora señala que si las

"demandadas hubiesen considerado que nuestra representada incurrió en algún incumplimiento grave de sus obligaciones contractuales (...), lo que era mínimamente esperable es que éstas ejercieran su derecho a poner término anticipado al Contrato".

Se desprende de la citada argumentación, que el remedio resolutorio o los hechos que lo articulan habrían caducado o fueron convalidados por el mandante.

${ }^{65}$ Chilena Consolidada con Iberia Líneas Aéreas (2012): "Sin perjuicio que las estipulaciones de los contratantes puedan modificar las reglas que van a expresarse, siempre y cuando ello no importe la condonación del dolo futuro -pues en esa estipulación habría objeto ilícito según lo establece el artículo 1465 del Código Civil, de acuerdo a lo prescrito en el artículo 1558 del mismo cuerpo legal, en caso de atribuirse responsabilidad a título de culpa, el deudor deberá indemnizar los perjuicios directos y previstos; en cambio, si puede imputársele dolo al deudor, deberá responder por los perjuicios directos, previstos e imprevistos". En el mismo sentido: Carlson Wagonlit con DHL Express (2011).

${ }^{66}$ Como la culpa grave se asimila al dolo en materia civil, no puede condonarse anticipadamente la culpa grave. VIAL (2003), p. 219. 
Pero el planteamiento anterior olvida que todos los remedios al incumplimiento, entre ellos, la facultad resolutoria establecida en el art. 1489 del Código Civil deben examinarse desde la perspectiva del interés del acreedor. Pues producido el incumplimiento contractual, es este quien tiene la facultad de resolver el contrato.

De este modo, si en la especie concurrieron las condiciones para que procediera la terminación de los contratos, la opción de resolverlos pertenece exclusivamente como acreedor al mandante; constituyendo un derecho meramente potestativo de ejercicio judicial -en el caso de la cláusula 38.4 en cuestión- bastando la demanda de resolución para entender que se ha decidido terminar los contratos ${ }^{67}$.

\section{No siempre la lógica económica-jurídica llama}

a poner término de manera inmediata a un contrato

Acontecido el incumplimiento, no parece sensato esperar siempre que el acreedor insatisfecho demande de manera inmediata la terminación. Si fuere así, no se entendería por qué el legislador entrega un plazo de prescripción de cinco años para hacer efectiva la acción resolutoria. Asimismo, entre el incumplimiento y la interposición de la acción de terminación del contrato, puede el acreedor entenderse con su deudor con el objetivo de que este último efectúe todas las actuaciones necesarias para que la prestación comprometida -y no ejecutada de acuerdo con el programa contractual- se ajuste a este y pueda satisfacer la prestación comprometida ${ }^{68}$. En fin, otorgar un plazo razonable a la constructora para subsanar sus incumplimientos antes de instar por la resolución inmediata del contrato ${ }^{69}$, parece unas de aquellas medidas de colaboración que surgen en contratos complejos como los de construcción ${ }^{70}$.

39. El planteamiento de la constructora llevaría al absurdo de que su acción resolutoria también habría caducado

De seguirse el planteamiento de la constructora, no se entiende cómo aquella podría sostener estar habilitada para resolver los contratos. En efecto, recordemos que la primera obligación que imputa incumplida por el mandante es la falta de entrega de la totalidad de los planos desde el inicio de los trabajos. A su

${ }^{67}$ Véase Pizarro (2009), pp. 221-258.

${ }^{68}$ LÓPEZ (1998), p. 427.

${ }^{69}$ Se ha señalado que, de este modo, habría una ponderación entre el principio de conservación del contrato y el interés de desligarse del mismo. Palazón (2014), p. 141. En este sentido, los instrumentos internacionales de derecho uniforme, han optado por otorgar al deudor un plazo razonable para cumplir su prestación. De no mediar dicho cumplimiento, procedería la resolución del contrato de así preferirlo el acreedor. Por ejemplo, arts. 47.1 y 63.1 de la Convención de Viena y arts. 8:106 y 9:301 de los Principios Europeos de Derecho de Contratos.

${ }^{70}$ Se ha señalado: "Así, en contratos que contemplan obligaciones primordiales de hacer, como el mandato, o el contrato de construcción, entre otros, es usual que atendida la duración de la convención, la naturaleza de las obligaciones involucradas o la entidad económica del contrato, las partes hayan incluido deberes de colaboración”. Prado (2016), pp. 59-83. 
juicio, dicha obligación era esencial. Sin embargo, la constructora no demandó la terminación de los contratos. En su lugar, optó por mantenerse en obra por largos años luego de aquel supuesto incumplimiento ¿ Podríamos sostener que la constructora hizo caducar su derecho a deducir la acción de resolución? Creemos que no. Siempre de haber mediado, por cierto, un incumplimiento contractual de carácter esencial de parte del mandante.

\section{Conclusiones}

\section{A. Sobre la calidad de experto de la constructora}

1. La calidad de experto de un contratante necesariamente agrava el nivel de diligencia y cuidado que debe emplear al ejecutar sus obligaciones. De allí que el estándar de conducta exigible a la constructora, sociedad que emprende tareas delicadas y complejas, resulte ser comparativamente superior al aplicable respecto de quienes carecen de esas calificaciones.

\section{B. Sobre los contratos de construcción de naturaleza Fast Track}

2. El sentido y alcance de la modalidad denominada fast track, debe ser buscada en la doctrina y jurisprudencia anglosajona. De acuerdo con aquellas, fast track se define como un método de construcción en el cual la construcción comienza bajo una programación simultánea a la de la confección y terminación del diseño de la arquitectura e ingeniería del proyecto, de modo que naturalmente la constructora no podía esperar al inicio de los trabajos, la entrega de la totalidad de los planos.

\section{Las obligaciones del constructor se encuentran sujetas a una responsabilidad de carácter objetiva}

3. La obligación de la constructora de entregar correcta, completa y oportunamente las obras encomendadas en los contratos, es una de aquellas de resultado. La constructora se obligó naturalmente respecto del mandante a la obtención de lo proyectado en aquellos instrumentos (la ejecución de la planta); teniendo la constructora que encaminar toda su actividad para concretar aquel resultado, no bastando la prueba de la diligencia para excusar su incumplimiento.

\section{La obligación de poner adecuadamente en funcionamiento las obras (precomisionamiento) corresponde contractualmente a la constructora y no al Administrador contratado en modalidad EPCM}

Si el precomisionamiento es propiamente una labor de construcción para terminar los trabajos encomendados, resulta forzoso concluir que era la constructora 
quien debía realizarlo, pues al administrador se le encomendó la función de coordinar técnico y no de constructor. Ratifica lo anterior, que en el proceso de licitación la constructora incorporó estos trabajos en su programa, con el objetivo de obtener el término mecánico de los trabajos, hito que debía cumplir precisamente para lograr la recepción provisional de las obras.

\section{E. El mandante se encuentra habilitado a modificar el alcance de su proyecto}

Las partes reconocen la facultad que tiene el mandante para introducir modificaciones, obras adicionales y extraordinarias al proyecto, incluso posteriormente al inicio de los trabajos. En efecto, aquello será lo natural al encontrarnos frente a contratos fast track, que normalmente se pactan a serie de precios unitarios, y en los que la ingeniería aún se encuentra en desarrollo durante la ejecución de las obras, de modo que la incorporación de una u otra partida resultará normal y previsible para el constructor.

\section{F. Sobre la aplicación de las multas contractuales}

Al haber asumido la constructora obligaciones de resultado, solo podrá enervar el cobro de las cláusulas penales o multas pactadas, acreditando el cumpli-

312 miento de sus "compromisos administrativos" y su obligación de entregar las obras de forma correcta, completa y oportuna o, en su defecto, el acaecimiento de un caso fortuito. A juicio de este informante, la caducidad como medio de extinguir las obligaciones es excepcional en materia civil, no teniendo aplicación en el caso en estudio al no existir norma legal ni convencional que la establezca en favor de la constructora frente al devengo de multas. En aquellos términos, el transcurso del tiempo como forma de extinguir las obligaciones solo podría operar de acuerdo con las reglas de la prescripción, lo que no ha acontecido. Estos informantes tampoco vislumbran que exista renuncia o remisión de la obligación penal. Siendo vigentes y actualmente exigibles las penas establecidas contractualmente por las partes, tanto el mandante como el administrador disponen de la facultad para hacer efectivos esos cobros a través del procedimiento arbitral.

\section{G. La naturaleza de los backcharges o cargos al subcontratista}

Atendido el objeto de la medida correctiva denominada contractualmente como backcharges, se desprende que aquella busca -dentro de los plazos de ejecución de los trabajos pactados- garantizar la obtención de la misma prestación establecida en los contratos. Por ello es que los backcharges disponen la naturaleza propia de cumplimiento y no de resarcimiento. Para su procedencia no debe establecerse que el incumplimiento ha generado perjuicios, pues la regulación respecto de ellos -como posibles agravantes o limitaciones- resulta inaplica- 
ble. Basta, entonces, que la constructora haya incumplido los contratos para que este remedio contractual cobre aplicación. De contrario se confundiría el cumplimiento forzado con la indemnización de perjuicios.

\section{H. La aplicación de las garantías a la construcción de las obras: El caso del montaje de cañerías}

La cláusula de "garantía de calidad" establece al cumplimiento en naturaleza como remedio contractual. "Reparar y/o rehacer", significa para el mandante la obtención misma de la prestación de la constructora (la construcción), sea que provenga de aquella misma o de un tercero. Estimamos que si el montaje de cañería era parte de la obligación contractual de la constructora, aquel trabajo debía ser entregado al mandante libre de defectos. En caso contrario, el mandante dispone de la posibilidad de contratar a terceros para ejecutar -con cargo a la constructora- las reparaciones a las obras hasta obtener los parámetros constructivos acordados por las partes. Sin embargo, pensamos que dentro de los costos a ser reembolsados por el contratista al mandante no deben considerarse los pagos realizados a consultores o expertos para determinar los defectos, pues es precisamente el mandante quien debía acreditar dicha circunstancia para que esta regla tuviera cabida.

\section{Sobre la indemnización de daños: interpretación a los límites a la responsabilidad civil de las partes}

La correcta interpretación de las cláusulas $37^{\mathrm{a}}$ de las BAE y de las BAG, llama a encuadrar su aplicación sobre la constructora, quien es el sujeto que ha limitado su derecho a ser indemnizado. Asimismo, el término "parte afectada" que se señala en las BAE -a la luz de las BAG- se están refiriendo al administrador y al mandante, siendo estos quienes podrían sortear la cláusula limitativa de responsabilidad, y demandar por "negligencia, culpa, dolo o conducta ilegal" de la constructora. Lo usual es que los contratantes limiten o excluyan su responsabilidad civil por actos meramente culposos, y que sea ante actuaciones maliciosas que las reglas generales establecidas en el Código Civil cobren aplicación, por ello es que de conformidad al art. 1562 del Código Civil, de bastar la mera negligencia para excluir la aplicación de la cláusula limitativa de responsabilidad, en la práctica se le estaría dejando sin efecto; y el "sentido en que una cláusula puede producir algún efecto, deberá preferirse a aquel en que no sea capaz de producir efecto alguno".

\section{J. La facultad del acreedor para terminar el contrato.}

$\mathrm{Si}$ en la especie concurrieron las condiciones para que procediera la terminación de los contratos, la opción de resolverlos pertenece exclusivamente como acreedor -de conformidad al art. 1489 del Código Civil- al mandante; 
constituyendo un derecho meramente potestativo de ejercicio judicial -en el caso de la cláusula 38.4 en cuestión- bastando la sola demanda de resolución para entender que se ha decidido terminar los contratos.

\section{Bibliografía CitADA}

Abeliuk Manasevich, René (2014). Las obligaciones. Santiago: Thomson Reuters. Acosta Ramírez, Vicente (1998). "Modificaciones legales y convencionales de los montos de las indemnizaciones". Revista de Derecho de la Universidad Católica de Valparaíso. Vol. XIX Valparaíso.

Alcalde Rodríguez, Enrique (2008). "La cláusula de declaraciones y garantías en la venta de una empresa: naturaleza jurídica y efectos". Revista Actualidad Jurídica. n. $^{\circ}$ 17. Santiago.

Alhomadi, Ahmad A., Reza Dehghan \& Janaka Y. Ruwanpura (2011) The predictability of fast-track projects. Procedia Engineering. Amsterdam: ScienceDirect, Elsevier.

Bahamondes Oyarzún, Claudia (2011). "Concurrencia de la indemnización de daños y la pretensión de cumplimiento específico frente al incumplimiento contractual". Cuaderno de Análisis Jurídico. Incumplimiento contractual, nuevas perspectivas. Santiago: Ediciones Universidad Diego Portales, Escuela de Derecho. Colección Derecho Privado VII.

Barcia Lehmann, Rodrigo (2007). "La asimilación de la culpa al dolo desde una perspectiva objetiva del derecho de los contratos. Revista Ius et Praxis. Vol. 13, n. ${ }^{\circ}$ 1. Talca.

Barros Bourie, Enrique (2006). Tratado de responsabilidad extracontractual. Santiago: Editorial Jurídica de Chile.

Barros Bourie, Enrique (2007). "Finalidad y alcance de las acciones y remedios contractuales", en Alejandro GuzMán Brito (ed. científico), Estudios de Derecho Civil III, Valparaíso: Thomson Reuters.

Barros Bourie, Enrique y Nicolás Rojas Covarrubias (2009). "Responsabilidad por declaraciones y garantías contractuales", en UNIVERSIDAD DE CONCEPCIÓN (coord.). Estudios de Derecho Civil V. Santiago: AbeledoPerrot.

Contreras Strauch, Osvaldo y Arturo Prado Puga (1996). El contrato de construcción y sus principales garantías. Santiago: Colegio de Abogados de Chile AG.

Corral Talciani, Hernán (2012). La cláusula penal. Santiago: Editorial Jurídica de Chile.

Del Arco Torres, Miguel y Manuel Pons González (1991). Derecho de la Construcción. Madrid: Editorial Comares S.L.

Dhghan, Reza \& Janaka Ruwanpura (2011). "The mechanism of design activity overlapping in constructionprojects and the time-cost tradeoff function". Procedia Engineering. Vol. 14, Ámsterdam.

Díez-Picazo, Luis, Encarna Roca Trías y Antonio-Manuel Morales Moreno (2002). Los principios del Derecho Europeo de Contratos. Madrid: Editorial Civitas. 
Domínguez Hidalgo, Carmen (2010). "El problema de la culpa presunta contractual y las obligaciones de medio y resultado: sus implicancias para la responsabilidad médica". Cuadernos de Análisis Jurídico. Santiago: Ediciones Universidad Diego Portales, Escuela de Derecho. Colección Derecho Privado VI.

Friedlander, Mark C. (2011). "Construction project delivery methods: Which is best for you?”, in Illinois State Bar Association, Building Knowledge Newsletter. Disponible en www.isba.org/sections/construction/newsletter/2011/05/constructionprojectdeliverymethodsw. [Fecha de consulta: 20 de noviembre de 2017].

Furst, Stephen, Vivian Ramsey, Adrian Williamson \& John UfF (2006). Keating on construction contracts. London: Sweet \& Maxwell.

García Miro, Mario (2015). La Due Diligence Legal y sus efectos en la compraventa de empresas. Tesis de grado para obtención de título de Máster en derecho de empresa y los negocios. Barcelona: Universidad de Barcelona. Disponible en http://diposit.ub.edu/dspace/bitstream/2445/67950/1/TFM_mario\%20 garcia $\% 20$ miro.pdf. [Fecha de consulta: 16 de noviembre de 2017].

Gómez Pomar, Fernando (2007). "El incumplimiento contractual en Derecho español". Revista para el Análisis del Derecho. n. ${ }^{\circ}$ 3. Barcelona.

González CAstillo, Joel (2011). "Las cláusulas limitativas, exonerativas o agravantes de responsabilidad en materia contractual. Validez y límites". Revista Chilena de Derecho. Vol. 38. n. ${ }^{\circ}$ 1. Santiago.

ICE (2011). Manual of Construction Law. London: ICE-Institution.

Kemelmajer de Carlucci, Aida y Carlos Parellada (1997). "Los factores subjetivos de atribución”, en Jorge Mosset Iturraspe (dir.). Responsabilidad civil. Buenos Aires: Hammurabi.

KnOwles, Roger (2012). 200 Contractual problems and their solutions. London: WileyBlackwell.

López López, Ángel (1998) “Artículo 48”, en Luis Díez Picazo y Ponce de León, La compraventa internacional de mercaderías. Comentario de la Convención de Viena. Madrid: Editorial Civitas.

López Santa María, Jorge (2010). Los contratos. Parte general. Santiago: AbeledoPerrot.

Mazeaud, Henri y André Tunc (1961). Tratado teórico y práctico de la responsabilidad civil delictual y contractual. Buenos Aires: Ediciones Jurídicas Europa-América.

Morales Moreno, Antonio-Manuel (2014). "Claves de la modernización del derecho de contratos”, en Antonio Manuel Morales Moreno, Álvaro Vidal Olivares, Íñigo de la Maza Gazmuri, Estudios de Derecho de Contratos. Formación cumplimiento e incumplimiento. Santiago: AbeledoPerrot.

Palazón Garrido, María (2014). Los remedios frente al incumplimiento en el derecho comparado. Navarra: Editorial Aranzandi.

Pantaleón Prieto, Fernando (1995). "Voz 'Incumplimiento"”. Enciclopedia jurídica básica, Madrid, Civitas. Tomo III. 
Peñailillo Arévalo, Daniel (2003). Obligaciones. Teoría general y clasificaciones. La resolución por incumplimiento. Santiago: Editorial Jurídica de Chile.

Peñailillo Arévalo, Daniel (2008). "Responsabilidad contractual objetiva", en Carlos Pizarro Wilson (coord.). Estudios de Derecho Civil IV, Olmué, Chile: Thomson Reuters.

Pizarro Wilson, Carlos (2008). "La culpa como elemento constitutivo del incumplimiento en las obligaciones de medio o de diligencia". Revista de Derecho de la Pontificia Universidad Católica de Valparaíso. Vol. xxxi, Valparaíso.

Pizarro Wilson, Carlos (2009). "Diligencia, incumplimiento y exoneración de responsabilidad", en Gonzalo FigueroA YañEz (coord.) Estudios de Derecho Civil $V$. Santiago: AbeledoPerrot.

Prado López, Pamela (2016). "La inobservancia al deber de colaboración del acreedor en el derecho chileno: un caso de incumplimiento contractual". Revista de Derecho, Vol .29. n. ${ }^{\circ}$ 2. Valdivia.

Prado Puga, Arturo (2014). "El contrato general de construcción y en especial la modalidad EPC y sus principales características. Revista Chilena de Derecho, Vol. 41. n. ${ }^{\circ}$ 2. Santiago.

Ríos Salas, Víctor y Carlos Molina Zaldívar (2016). Derecho de la Construcción. Santiago: O'Print Impresores S.A.

Rodríguez Pinto, María Sara (2008). "Incumplimiento y exoneración de responsabilidad en los contratos de prestación de servicios. Los lineamientos de la responsabilidad estricta del proveedor”, en Alejandro GuZMÁn BRITO (coord.). Estudios de Derecho Civil III, Valparaíso, LegalPublishing.

SQuires, William R. \& Michael J. MurPhy (1983). "The impact of fast track construction and construction management on subcontractors". Law and contemporary problems. Vol. 46. n. $^{\circ}$ 1. Washington.

Sweet, Justin \& Marc M. SchneIER (2009). Legal Aspects of Architecture, Engineering and the Construction Process. Ninth Edition. Stamford: Cengage Learning.

Vera González, María Eugenia (2007). Identificación de los elementos que producen las controversias en contratos de la industria de la construcción y proposición de acciones preventivas. Memoria para optar al título de ingeniero civil. Santiago: Universidad de Chile, Departamento de Ingeniería Civil.

Vial del Río, Víctor (2003). Manual del Derecho de las obligaciones en el Código Civil chileno. Santiago: Editorial Biblioteca Americana.

Vidal Olivares, Álvaro (2007). “Cumplimiento e incumplimiento contractual en el Código Civil. Una perspectiva más realista. Revista Chilena de Derecho. Vol. 34. n. ${ }^{\circ}$ 1. Santiago.

Vidal Olivares, Álvaro (2009). "La noción de incumplimiento esencial en el 'Código Civil'”. Revista de Derecho de la Pontificia Universidad Católica de Valparaíso. Vol. Xxxir. Valparaíso. 


\section{Jurisprudencia citada}

Corte Suprema

ACE Seguros con FCAS. Ingeniería (2008): Corte Suprema, 10 de diciembre de 2008 (recurso de casación en la forma y fondo), rol 1.771-2007.

Carlson Wagonlit con DHL Express (2011), Corte Suprema, 28 de diciembre de 2011 (recurso de casación en el fondo), rol 2800-2011.

Chilena Consolidada con Iberia Líneas Aéreas (2012): Corte Suprema, 14 de mayo de 2012 (recurso de casación en el fondo), rol 750-2012.

Consejo de Defensa del Estado con Empresa Constructora Bravo Izquierdo (2014): Corte Suprema, 10 de junio de 2014 (recurso de casación en el fondo), rol 9.996-2014.

Davis Autos S.A. con General Motors Chile (2014): Corte Suprema 19 de junio de 2014 recurso de casación en la forma y fondo), rol 2.881-2013.

Inversiones Clarkson con Donoso C., Humberto (2014): Corte Suprema, 29 de mayo de 2014 (recurso de casación en la forma y fondo), rol 2.073-2013.

Vidal Heuisler, Jaime y otros con Hospital Clínico de la Pontificia Universidad Católica de Chile (2016): Corte Suprema, 19 de enero de 2016 (recurso de casación en la forma y fondo), rol 7.215-2014.

Cortes de Apelaciones

Consejo de Defensa del Estado con Empresa Constructora Bravo Izquierdo (2014): Corte de Apelaciones de Punta Arenas, 22 de marzo de 2014 (recurso de apelación), rol 61-2013.

Davis Autos S.A. con General Motors Chile (2013). Corte de Apelaciones de Santiago, 13 de marzo de 2013 (recurso de apelación), rol 5.516-2011.

Cortes de Apelaciones de Estados Unidos

Roberts \& Schaefer Co. con Hardaway Co. (1998): Court of Appeals for the Eleventh Circuit, August 31, 1998 (appeal), docket 97-2664.

Marriott Corporation con Dasta Construction Company (1994): Court of Appeals for the Eleventh Circuit, July 22, 1994 (appeal), docket 92-2981.

Comstock \& Company, Inc. con United Engineers \& Constructors Inc. (1989): Court of Appeals for the Ninth Circuit ( (appeal), docket 87-2502. 